\title{
Perioperative therapy for locally advanced gastroesophageal cancer: current controversies and consensus of care
}

\author{
Amikar Sehdev and Daniel VT Catenacci ${ }^{*}$
}

\begin{abstract}
Gastroesophageal cancer (GEC) remains a challenging problem in oncology. Anatomically, GEC is comprised of distal gastric adenocarcinoma (GC), classically associated with Helicobacter Pylori, while proximal esophagogastric adenocarcinoma (EGJ AC) has increased significantly in incidence over the past years. Despite contrasting etiologies, histologies, and molecular phenotypes of distal and proximal GEC, in many cases perioperative (and metastatic) treatment strategies converge to similar approaches. For patients undergoing curative intent surgery, advances in perioperative chemotherapy and/or chemoradiotherapy, either before and/or after surgery, have demonstrated improved survivals compared to surgery alone. This review focuses on how the 'boundary' of the Z-line and/or the anatomical distinction of 'proximal' (EGJ) vs. 'distal' (GC) cancer has led to diverse inclusion/exclusion criteria for clinical trial enrollment, embodying various combinations of chemotherapy and radiation before and/or after surgery. Supporting evidence of each of these approaches consequently has led to a number of varying practices by geographical region and Institution/Physician, based on differing experience, preference, and clinical circumstance. Adequate direct comparison of these approaches is lacking currently, but data from a number of concerted efforts should be available in the next years to further direct best standards of care. Introduction of biologically targeted agents, namely anti-angiogenics and anti-HER family therapeutics are being evaluated to determine whether further therapeutic gains can be realized over classic cytotoxic chemotherapy alone (with/without radiotherapy). To date, novel molecularly targeted agents have yet to demonstrate benefit in this setting. In the following comprehensive review we will address the intricacies of perioperative treatment of locally advanced GEC, with focus on clinical trials supporting the diverse set of perioperative multidisciplinary approaches.
\end{abstract}

Keywords: Gastric adenocarcinoma, Stomach cancer, Esophageal adenocarcinoma, Esophagogastric (gastroesophageal) junction cancer, Chemotherapy, Chemoradiotherapy, Multi-disciplinary care

\section{Current curative standards and controversies}

Gastroesophageal adenocarcinoma (GEC) is a complex disease which can be broadly classified into proximal esophagogastric junction (EGJ) and distal gastric cancer (GC) [1]. At present, surgery is the sole curative option for operable GEC. Endoscopic mucosal resection (EMR) is also a possible local therapy for well-differentiated, non-depressed tumors that are less than $2 \mathrm{~cm}$ in size and invading only up to superficial muscularis (T1a) [2]. EMR for T1aNo disease is associated with 5-year survival comparable to surgery and has relatively low mortality

\footnotetext{
* Correspondence: dcatenac@medicine.bsd.uchicago.edu

Department of Medicine, Section of Hematology Oncology, University of Chicago, 5841 S. Maryland Avenue, MC 2115, Chicago, IL 60637, USA
}

and morbidity [3]. EMR alone is currently still controversial for T1b (sm1), with reports of 1-3\% LN involvement, while sm2 and sm3 have 10-30\% LN involvement [3]. Additionally, EMR can be curative for poorly differentiated intramucosal lesions less than $1 \mathrm{~cm}$, and in nonpoorly differentiated or non-ulcerated tumors less than $2 \mathrm{~cm}$ in size [4].

For more advanced disease, the type of surgical approach and extent of surgery depends upon the anatomical location, extent, and TNM stage of the tumor, and is beyond the scope of this review [3]. For the most part, there is consensus regarding surgical approach for Siewert type I (considered esophageal cancers), treated by either an en bloc transthoracic or transhiatal esophagectomy with two-field

\section{() Biomed Central}

(c) 2013 Sehdev and Catenacci; licensee BioMed Central Ltd. This is an Open Access article distributed under the terms of the Creative Commons Attribution License (http://creativecommons.org/licenses/by/2.0), which permits unrestricted use, distribution, and reproduction in any medium, provided the original work is properly cited. 
lymphadenectomy. For type III EGJ tumors (gastric cardia), a total gastrectomy via laparotomy and D2 lymphadenectomy without routine distal splenopancreatectomy is recommended. For Siewert type II EGJ tumors, either of these procedures are accepted approaches [3,5]. Although there is some controversy, proximal stomach tumors (including gastric cardia) require either a total gastrectomy or proximal gastrectomy with resection of 5 to $10 \mathrm{~cm}$ of esophagus. Tumors of the middle third/fundus of the stomach usually require a total gastrectomy, however tumors of the distal third of the stomach can undergo radical subtotal (75-85\%) gastrectomy [6]. Most trials have demonstrated that achieving a R0 resection is critical and is prognostic of improved 5-year survival for both EGJ and $\mathrm{GC}$, in contrast to $\mathrm{R} 1 / \mathrm{R} 2$ resection (microscopic/ macroscopic tumor) [7].

With respect to D1 versus D2 dissection, a recent metaanalysis evaluating 5 RCTs, involving 1642 patients with GC enrolled from 1982 to 2005, revealed a higher operative mortality associated with D2 dissections in the earlier trials, while recent trials have similar rates of mortality between D2 and D1 lymphadenectomy [8]. A trend of improved survival existed among D2 patients who did not undergo resection of the spleen or pancreas, as well as for patients with T3/T4 cancers. Given that D2 resections may improve the accuracy of locoregional staging and may improve survival when avoiding routine distal pancreatectomy and splenectomy, most agree that this modified D2 approach is appropriate and has been accepted as standard of care in the recent NCCN guidelines [9]. The D1 versus D2 variable plays a significant role when comparing results across various trials (reported and ongoing) that will be discussed below.

The complexity and heterogeneity of GEC, in terms of patient ethnicity [10], as well as anatomical, histological, and molecular subsets, has resulted in a number of categorizations, perioperative treatment strategies, and surgical approaches $[1,11]$. Specifically, the anatomical distinction of 'proximal' (EGJ) versus 'distal' (GC) cancer has led to diverse inclusion/exclusion criteria for clinical trial enrollment, embodying various combinations of chemotherapy and radiation before and/or after surgery (Figure 1). Supporting evidence of each of these approaches consequently has led to a number of different practices by

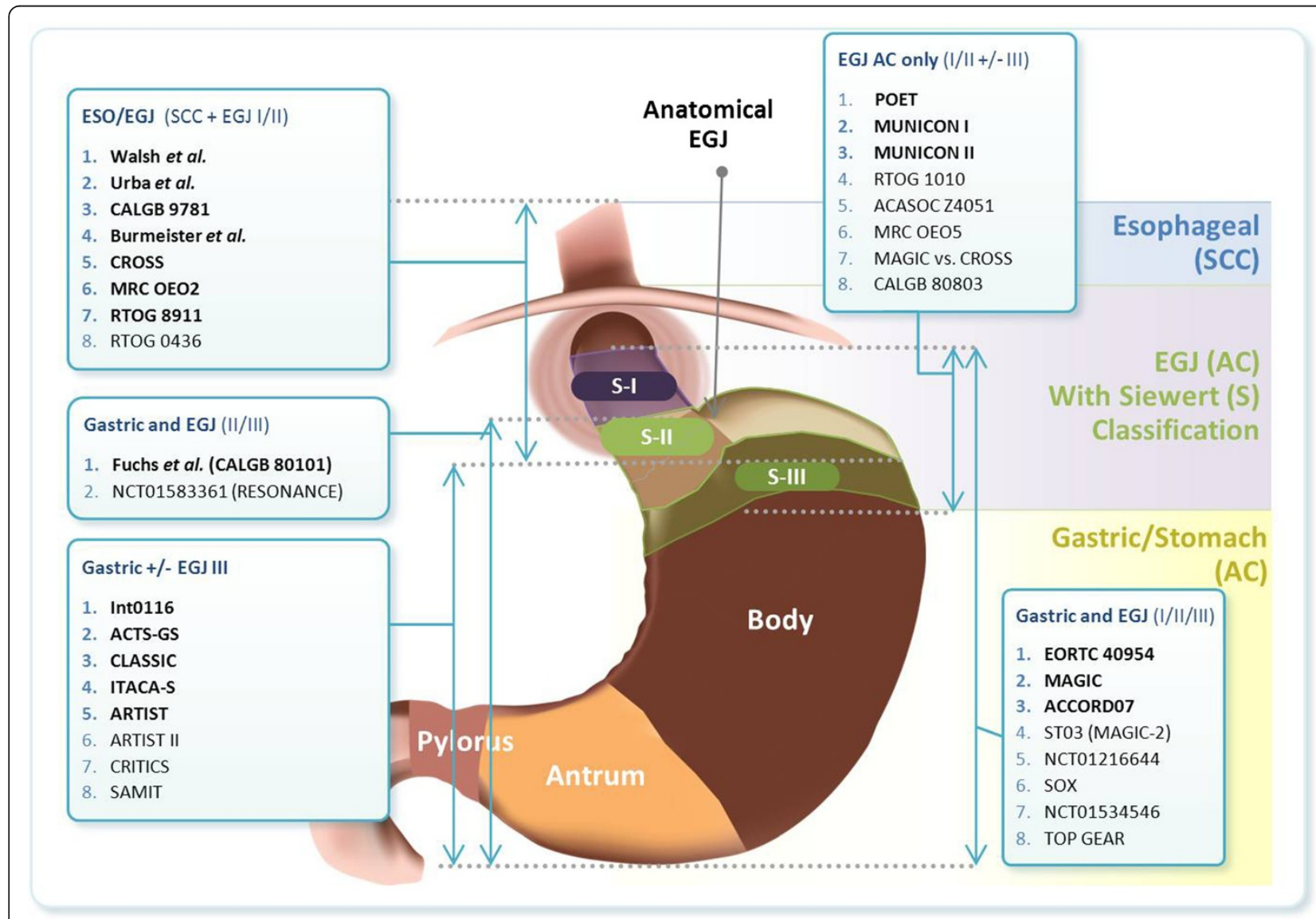

Figure 1 Completed and ongoing perioperative gastroesophageal adenocarcinoma clinical trials, demonstrating enrollment criteria by tumor location. See text and tables for trial references. Abbreviations: SCC, squamous cell carcinoma; EGJ, esophagogastric junction; AC, adenocarcinoma. Bolded: clinical trials with results reported; Not Bolded: clinical trials that are ongoing. 
geographical region and Institution/Physician, based on varying experience and preference, and discussed in further detail below.

\section{Modalities of perioperative treatment}

Surgery is the required modality of curative intent treatment of locally advanced GEC. Occult peritoneal disease as the sole site of dissemination reportedly occurs in approximately $20-25 \%$ of GEC patients, according to several large retrospective analyses [1]. Perioperative debulking, hyperthermic intraperitoneal chemotherapy (HIPEC), and other novel immunological approaches have been evaluated as part of the curative intent strategy, mostly in Asia, recently reviewed elsewhere [1]. A number of clinical trials have established various perioperative treatment options that further improve mOS compared to surgery alone, including i) neoadjuvant chemoradiation $(\mathrm{CRT} \rightarrow \mathbf{S})$, ii) adjuvant CRT $(\mathbf{S} \rightarrow$ CRT), iii) neoadjuvant chemotherapy $(\mathbf{C} \rightarrow \mathbf{S})$, iv) adjuvant chemotherapy $(\mathbf{S} \rightarrow \mathrm{C})$, v) perioperative chemotherapy (sandwich approach) $(\mathrm{C} \rightarrow \mathbf{S} \rightarrow \mathrm{C})$, and vi) induction chemotherapy followed by neoadjuvant CRT $(\mathrm{C} \rightarrow \mathrm{CRT} \rightarrow \mathbf{S})$. The following is a summary of phase III trials supporting each of these strategies (Table 1; Figure 1).

\section{Comparisons to surgery alone}

i. Neoadjuvant chemoradiotherapy (CRT $\rightarrow S$ ) vs. surgery alone

Before 2010, there were four main trials in this category where a majority of patients enrolled had AC histology compared to SCC. All of these trials used cisplatin and 5-flourouracil along with radiation therapy (RT) [12-14] except the trial by Urba et al. which used cisplatin, 5fluorouracil and vinblastine along with RT [15]. The doses of RT ranged from 35 Gy [13] to 50.4 Gy [14]. In these trials, the majority of tumors were $\mathrm{AC}$ and located in the mid or distal thirds of the esophagus. Only two of the four trials showed a statistically significant survival advantage [12,14]; however, both of these trials are faced with criticism. The trial by Walsh et al. is widely criticized because of an unexpectedly low 3-year survival rate of $6 \%$ in the surgery alone arm versus $32 \%$ with trimodality therapy [12], compared to the $16-30 \%$ seen in the control arms of the other three trials, thus overestimating the clinical benefit of trimodality therapy. Both the trials of Walsh et al. and Tepper et al. were under accrued with small numbers of patients (total enrollment of 113 and 56, respectively) [12,14]. All four trials showed improvement in pathological complete response $(\mathrm{pCR})$, but with wide variability, ranging from $12-40 \%$. Given that these four trials were under-accrued, had conflicting outcomes, and were 'contaminated' with SCC tumors (despite having a majority AC), the relevance of the four randomized control trials for EGJ $\mathrm{AC}$ remained unclear and controversial. However, a metaanalysis that included these four trials along with 6 other neoadjuvant CRT trials, enrolling exclusively SCC patients, showed an overall benefit for all-cause mortality with HR 0.81 (95\% CI 0.70-0.93, p=0.002), and thus these data were used to support the use of neoadjuvant CRT for EGJ AC tumors [16]. An updated meta-analysis was recently reported, with HR 0.78 (95\% CI 0.7-.088; $\mathrm{p}<0.0001$ ) [17].

However, most recently the large 363 patient CROSS trial was reported, which ultimately enrolled EC (SCC) and EGJ (AC) in a 1:3 ratio, evaluating $\mathrm{CRT} \rightarrow \mathrm{S}$ (carboplatin/ paclitaxel/ 41.4Gy) versus $S$ alone [18]. This was the first large adequately accrued 'stand-alone' phase III trial to support neoadjuvant CRT over surgery alone in this patient population. There was a pCR of $29 \%$ ( $49 \%$ for SCC, $23 \%$ for $\mathrm{AC}$ ) and R0 resection rate of $92 \%$ versus $69 \%$ - for those patients actually receiving surgical resection (i.e. not intention-to-treat ITT). The overall $\mathrm{mOS}$ was 49.4 versus 24 months and HR was 0.67 (95\% CI 0.45-0.87, $\mathrm{p}=0.02$ ). However, the subgroup analysis by histology was HR 0.422 $(\mathrm{N}=88 ; 95 \%$ CI $0.24-0.79, \mathrm{p}=0.007)$ for SCC, and HR $0.741(\mathrm{~N}=275$; $95 \%$ CI 0.53-1.02, $\mathrm{p}=0.07)$ for AC. Despite these obvious clinically significant differences in outcome between histological subgroups, there was reportedly not a significant statistical interaction by histology. Based on these data, neoadjuvant CRT remains an accepted treatment option for EGJ AC tumors (Type I/II Siewert), particularly now with carboplatin/paclitaxel chemotherapy based on 'CROSS', and in particular in North America and the Netherlands. Awaited are the data detailing the differences in R0 resection rate, recurrence rates (local vs. distant), and 1, 3, 5 year survival rates between $\mathrm{AC}$ and SCC tumors between the two treatment groups. It is anticipated that the AC group will have derived less benefit from CRT, in terms of mOS, due to more distant recurrences as compared to SCC, despite improved local control.

\section{ii. Adjuvant chemoradiotherapy ( $\rightarrow$ $\rightarrow$ C-CRT-C) vs. surgery alone}

The landmark Macdonald/INT0116 trial randomized patients to receive adjuvant CRT (one cycle of bolus 5-FU monotherapy, followed by 2 cycles of 5-FU with concurrent RT (45Gy) for $\sim 5$ weeks, followed by 2 more cycles of 5-FU monotherapy) versus no adjuvant therapy in 556 patients with stage IB-IV (no distant metastasis, AJCC $6^{\text {th }}$ edition) GC (80\%) or EGJ (20\% type III Siewert) adenocarcinoma [19]. The regimen, referred to herein as the 'MacDonald Regimen', consisted of 5-FU and leucovorin administered before and after radiation. Chemotherapy ( 5 -FU, bolus $425 \mathrm{mg} / \mathrm{m} 2$ per day, and leucovorin, $20 \mathrm{mg} / \mathrm{m} 2$ per day, for 5 days) was initiated on day 1 and was followed by CRT beginning 28 days after the start of the initial cycle of chemotherapy. CRT consisted of $45 \mathrm{~Gy}$ of radiation at 180 cGy per day, five days per week for 


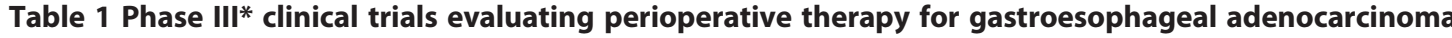

Study

\begin{tabular}{cllll} 
Inclusion & $\begin{array}{l}\text { Treatment and number } \\
\text { of patients }\end{array}$ & AC/SCC (\%) & ITT RO & PCR (\%) \\
\cline { 1 - 2 } AJCC $6^{\text {th }} \mathrm{Ed}$. & & & &
\end{tabular}

$\mathrm{T} / \mathrm{N}$

\section{i. Neoadjuvant CRT versus surgery alone}

\begin{tabular}{|c|c|c|c|c|c|c|c|c|c|c|c|}
\hline Walsh et al. [12], 1996 & $\begin{array}{l}\text { Locally advanced RT: } \\
40 \text { Gy }\end{array}$ & A: CRT (PF) $\rightarrow$ S: 58 & 100 & NR & A: 25 & NR & NR & \multicolumn{2}{|c|}{$\begin{array}{l}\text { Esophagus ( } 16 \text { middle } 1 / 3^{\text {rd }} \text {; } \\
51 \text { lower } 1 / 3^{\text {rd }} ; 34 \text { cardia) }\end{array}$} & 0 & $A: 32$ \\
\hline \multirow[t]{2}{*}{ Irish Trial } & & B: S: 55 & & & B: 0 & & & & & & B: 6 \\
\hline & & & & & & & & & & & $p=0.01$ \\
\hline \multirow[t]{3}{*}{$\begin{array}{l}\text { Burmeister et al. [13], } \\
2005\end{array}$} & T1-3, N0-1 & A: CRT (PF) $\rightarrow$ S: 128 & $62 / 37$ & A: 80 & $A: 12$ & A: 45 & $A: 11$ & $\begin{array}{l}\text { Esop } \\
\text { mid }\end{array}$ & $\begin{array}{l}\text { us (21, upper and } \\
13 ; 79 \text { distal } 1 / 3 \text { ) }\end{array}$ & 0 & $A: 32$ \\
\hline & RT: 35 Gy & B: S: 128 & & B: 59 & B: 0 & B: 41 & B: 14 & & & & B: 29 \\
\hline & & & & & & & & & & & $p=0.83$ \\
\hline Tepper et al. [14], 2008 & T1-3, Nx & $\mathrm{A}: \mathrm{CRT}(\mathrm{PF}) \rightarrow \mathrm{S}: 30$ & $75 / 25$ & NR & A: 40 & A: 27 & $A: 3$ & Tho & esophagus \& EGJ & 0 & A: 39 (5-year) \\
\hline \multirow[t]{2}{*}{ CALGB 9781} & RT: 50.4 Gy & B: S: 26 & & & B: 0 & B: 38 & B: 11 & & & & B: 16 \\
\hline & & & & & & & & & & & $p<0.002$ \\
\hline \multirow[t]{3}{*}{ Urba et al. [15], 2001} & Locally advanced & $\mathrm{A}: \mathrm{CRT}(\mathrm{PFV}) \rightarrow \mathrm{S}: 50$ & & NR & A: 28 & $A: 65$ & A: 19 & & & 0 & A: 30 \\
\hline & RT: 45 Gy & B: S: 50 & $75 / 25$ & & B: 0 & B: 60 & B: 42 & $\begin{array}{l}\text { Esop } \\
92 n\end{array}$ & $\begin{array}{l}\text { us (8 upper 1/3rd; } \\
\text { nd distal 1/3rd) }\end{array}$ & & B: 16 \\
\hline & & & & & & & & & & & $p=0.15$ \\
\hline $\begin{array}{l}\text { van Hagen et al. [18], } \\
2012\end{array}$ & T1N1 or T2-T3NO-1 & A: CRT (TP) $\rightarrow$ S: 175 & $75 / 25$ & 92 vs. 69 & A: 29 & $A: N R$ & $A: N R$ & 49 & 26 & 0 & A: 58 \\
\hline \multirow[t]{5}{*}{ 'CROSS' Trial } & $|\mathrm{b}-1| \mathrm{|b}$ & B: S: 188 & & & AC: $23 \%$ & B: NR & B: NR & & & & B: 44 \\
\hline & RT: 41.4 Gy & & & & B: 0 & & & & & & HR 0.65 (0.49-0.87) \\
\hline & & & & & & & & & & & $p=0.003$ \\
\hline & & & & & & & & & & & $\begin{array}{l}\text { Subgroup analysis for } \\
\text { AC only: HR } 0.74 \\
\text { (0.53-1.02) }\end{array}$ \\
\hline & & & & & & & & & & & $p=0.07$ \\
\hline \multicolumn{12}{|c|}{ ii. Adjuvant CRT versus surgery alone } \\
\hline $\begin{array}{l}\text { Macdonald et al. [19], } \\
2001\end{array}$ & $\begin{array}{l}\mathrm{T} 1-4 \mathrm{~N}+ \\
\mathrm{Ib}-\mathrm{IV}\end{array}$ & A: S: $\rightarrow$ CRT 281 & $100 / 0$ & NA & NA & A: 33 & A: 19 & 0 & 20 & 80 & A: 50 \\
\hline \multirow[t]{3}{*}{ Intergroup 0116} & RT: 45 Gy & $\begin{array}{l}C(5 F U)-C R T(5 F U)- \\
C(5 F U)\end{array}$ & & & & B: 18 & B: 29 & & & & B: 41 \\
\hline & & B: S: 275 & & & & & & & & & HR $0.76(0.62-0.96)$ \\
\hline & & & & & & & & & & & $p=0.005$ \\
\hline
\end{tabular}


Table 1 Phase III* clinical trials evaluating perioperative therapy for gastroesophageal adenocarcinoma (Continued)

\begin{tabular}{|c|c|c|c|c|c|c|c|c|c|c|c|c|}
\hline \multicolumn{13}{|c|}{ iii. Neoadjuvant chemotherapy versus surgery alone } \\
\hline \multirow[t]{4}{*}{ MRC OEO-2 [27], 2002} & Resectable cancer & $\mathrm{A}: \mathrm{C}(\mathrm{CF}) \rightarrow \mathrm{S}: 400$ & $66 / 31$ & A: 60 & NR & A: 12 & A: 8 & \multicolumn{2}{|l|}{64} & 10 & 0 & A: 43 (2 year) \\
\hline & & \multicolumn{2}{|l|}{ B: S: 402} & \multicolumn{2}{|l|}{ B: 54} & B: 10 & B: 8 & \multicolumn{3}{|c|}{ (26 SCC) } & & B: 34 \\
\hline & & & & & & & & & & & & HR $0.78(0.67-0.93)$ \\
\hline & & & & & & & & & & & & $p=0.004$ \\
\hline $\begin{array}{l}\text { Schuhmacher et al. [28], } \\
2010\end{array}$ & $\begin{array}{l}\text { T3 - T4, N0 - N + } \\
\text { (Locally Advanced) }\end{array}$ & $A: C(C F) \rightarrow S: 72$ & $100 / 0$ & A: 84 & A: 7 & NR & NR & 53 & & & 47 & A: 72.7 (2 year) \\
\hline \multirow[t]{2}{*}{ EORTC 40954} & & B: S: 72 & & B: 72 & B: 0 & & & & & & & B: 69.9 \\
\hline & & & & & & & & & & & & $p=0.46$ \\
\hline \multicolumn{13}{|c|}{ iv. Adjuvant chemotherapy versus surgery alone } \\
\hline $\begin{array}{l}\text { Sakuramoto et al. [31], } \\
2007\end{array}$ & $\begin{array}{l}\mathrm{T} 1-4 \mathrm{~N}+ \\
\|(\text { excluding } \mathrm{T} 1)-\| \mathrm{B}\end{array}$ & $\mathrm{A}: \mathrm{S} \rightarrow \mathrm{C}(\mathrm{S} 1) 529$ & $100 / 0$ & NA & NA & A: 21.4 & A: 2.8 & 0 & 0 & 0 & 100 & A: 80 \\
\hline \multirow[t]{3}{*}{ ACTS-GS Trial } & & B: S: 530 & & & & B: 27.1 & B: 1.3 & & & & & B: 70 \\
\hline & & & & & & & & & & & & HR $0.68(0.5-0.87)$ \\
\hline & & & & & & & & & & & & $p=0.003$ \\
\hline Bang et al. [34], 2012 & $T-4 N+$ or $\|-\| B B$ & A: S $\rightarrow$ C (CapeOx): 520 & $100 / 0$ & NA & NA & A: 18 & $A: 4$ & 0 & 0 & 2.5 & 97.5 & A: 74 (3-year DFS) \\
\hline \multirow[t]{3}{*}{ 'CLASSIC' Trial } & & B: S: 515 & & & & B: 26 & B: 8 & & & & & B: 59 \\
\hline & & & & & & & & & & & & HR $0.56(0.44-0.72)$ \\
\hline & & & & & & & & & & & & $p<0.0001$ \\
\hline \multicolumn{13}{|c|}{ v. Perioperative chemotherapy versus surgery alone } \\
\hline $\begin{array}{l}\text { Kelsen et al. [36,37], 1998, } \\
2007\end{array}$ & $|-|||$ & $\mathrm{A}: \mathrm{C}(\mathrm{CF}) \rightarrow \mathrm{S} \rightarrow \mathrm{CF} 233$ & $51 / 44$ & $A: 62$ & A: 2.5 & A: 49 & A: 19 & 51 & & & 0 & A: 26 \\
\hline \multirow[t]{2}{*}{ RTOG 8911} & Any N + & B: S: 234 & & B: 59 & B: 0 & B: 51 & B: 21 & & & & & B: 23 \\
\hline & & & & & & & & & & & & $p=0.53$ \\
\hline $\begin{array}{l}\text { Cunningham et al. [38], } \\
2006\end{array}$ & T1-4 N + or II-IV & $\begin{array}{l}\text { A: } C(E C F) \rightarrow S \rightarrow C \text { (ECF): } \\
250\end{array}$ & $100 / 0$ & $A: 69$ & 4 & A: 24 & A: 14 & 14 & 12 & & 74 & A: 36 (5-year) \\
\hline \multirow[t]{3}{*}{ 'MAGIC Trial' } & & B: S: 253 & & B: 66 & & B: 37 & B: 21 & & & & & B: 23 \\
\hline & & & & & & & & & & & & HR 0.75 (0.6-0.9) \\
\hline & & & & & & & & & & & & $p=0.009$ \\
\hline Ychou et al. [39], 2011 & T1-4 N + or II-IV & $\begin{array}{l}\text { A: C (CF) } \rightarrow S \rightarrow C(C F): \\
113\end{array}$ & $100 / 0$ & A: 84 & 3 & $A: 30$ & A: 24 & 11 & 64 & & 25 & A: 38 (5-year) \\
\hline FFCD9703 Trial & & & & & & B: 38 & B: 26 & & & & & B: 24 \\
\hline ACCORD 07 & & B: S: 111 & & B: 74 & & & & & & & & $\begin{array}{l}5-y r \text { HR } 0.69 \text { (0.5-0.95); } \\
p=0.02\end{array}$ \\
\hline
\end{tabular}


Table 1 Phase III* clinical trials evaluating perioperative therapy for gastroesophageal adenocarcinoma (Continued)

\begin{tabular}{|c|c|c|c|c|c|c|c|c|c|c|c|c|}
\hline \multicolumn{13}{|c|}{ vi. Comparison of post-operative chemotherapy regimens } \\
\hline Bajetta et al. [43], 2012 & $\mathrm{~N}+$ or N0 with T2b-4 & $\begin{array}{l}\text { A: S } \rightarrow \text { C (CPT-11+ } \\
\text { 5-FU/LV - TXT + CDDP): } \\
562\end{array}$ & $100 / 0$ & NA & NA & NR & NR & 0 & 0 & 15 & 85 & $\begin{array}{l}\text { No significant } \\
\text { difference }\end{array}$ \\
\hline $\begin{array}{l}\text { Abstract NCT01640782 } \\
\text { ITACA-S Trial }\end{array}$ & & $B: S \rightarrow C(5-F U / L V): 538$ & & & & & & & & & & $\begin{array}{l}\text { HR: } 1.00(0.83-1.20) ; \\
p=0.98\end{array}$ \\
\hline $\begin{array}{l}\text { Kobayashi Yoshida et al. } \\
{[44], 2012}\end{array}$ & $\mathrm{~T} 3-4, \mathrm{NO}-2$ & $\mathrm{~A}: \mathrm{S} \rightarrow \mathrm{C}(\mathrm{UFT}): 359$ & $100 / 0$ & NA & NR & NR & NR & None & & & 100 & $\begin{array}{l}\text { No significant } \\
\text { difference in DFS } \\
\text { between } C+D \text { and } \\
A+B\end{array}$ \\
\hline \multirow[t]{3}{*}{ 'SAMIT' Trial } & & $B: S \rightarrow C(S 1): 364$ & & & & & & & & & & $\begin{array}{l}\text { HR: } 0.92(0.80-1.07) ; \\
p=0.273\end{array}$ \\
\hline & & $C: S \rightarrow C(T->$ UFT): 355 & & & & & & & & & & \\
\hline & & $D: S \rightarrow C(T->S 1): 355$ & & & & & & & & & & \\
\hline \multicolumn{13}{|c|}{ vii. Adjuvant CRT comparing peri-RT chemotherapy regimens } \\
\hline Fuchs et al. [46], 2011 & Locally Advanced & $\begin{array}{l}\mathrm{A}: \mathrm{S} \rightarrow \mathrm{C}(5 \mathrm{FU} / \mathrm{LV}) \rightarrow \\
\mathrm{CRT}(5 \mathrm{FU}) \rightarrow \mathrm{C}(5 \mathrm{FU} / \mathrm{LV}): \\
280\end{array}$ & $100 / 0$ & NR & NR & NR & NR & None & & & 100 & A: 50 \\
\hline CALGB 80101 & & $\begin{array}{l}\text { B: } S \rightarrow C \text { (ECF) } \rightarrow \text { CRT } \\
(5 F U) \rightarrow C \text { (ECF): } 266\end{array}$ & & & & & & & & & & B: 52 \\
\hline NCT00052910 & & & & & & & & & & & & $\begin{array}{l}\text { HR } 1.03(0.80-1.34) \\
p=0.80\end{array}$ \\
\hline \multicolumn{13}{|l|}{ viii. PET directed therapy } \\
\hline Lordick et al. [50], 2007 & $\begin{array}{l}\text { CT3/4 Locally } \\
\text { advanced }\end{array}$ & $\begin{array}{l}C(C F) \rightarrow \text { Assess for } \\
\text { metabolic response }\end{array}$ & $100 / 0$ & NA & A: 58 & NR & $N R$ & 68 & 32 & 0 & 0 & A: Not reached \\
\hline \multirow[t]{3}{*}{ Phase II Municon trial } & & A: Response $\rightarrow C \rightarrow$ S: 54 & & & B: 0 & & & & & & & $\begin{array}{l}\text { B: } 25.8 \text { ( } 2.3 \text { years } \\
\text { median follow up) }\end{array}$ \\
\hline & & B: No-Response $\rightarrow$ S: 56 & & & $\begin{array}{l}\text { (Major Histologic } \\
\text { Response) }\end{array}$ & & & & & & & $\mathrm{HR}=2.13(1.14-3.99)$ \\
\hline & & & & & & & & & & & & $P=0.015$ \\
\hline $\begin{array}{l}\text { zum Buschenfelde et al. } \\
\text { [52], } 2011\end{array}$ & $\begin{array}{l}\text { cT3/4 Locally } \\
\text { advanced }\end{array}$ & $\begin{array}{l}C(C F) \rightarrow \text { Assess for } \\
\text { metabolic response }\end{array}$ & $100 / 0$ & $\mathrm{NA}$ & A: 36 & A: 30 & A: 9 & 69 & 31 & 0 & 0 & A: 71 \\
\hline \multirow[t]{3}{*}{ Phase II Municon II } & & A: Response $\rightarrow C \rightarrow$ S: 33 & & & B: 26 & B: 48 & B: 17 & & & & & B 42 \\
\hline & & $\begin{array}{l}\text { B: No-Response } \rightarrow \text { CRT } \rightarrow \\
\text { S: } 23\end{array}$ & & & $\begin{array}{l}\text { (Major Histologic } \\
\text { Response) }\end{array}$ & & & & & & & $\mathrm{HR}=1.9(0.87-4.24)$ \\
\hline & & & & & & & & & & & & $P=0.10$ \\
\hline
\end{tabular}


Table 1 Phase III* clinical trials evaluating perioperative therapy for gastroesophageal adenocarcinoma (Continued)

ix. Induction chemotherapy followed by CRT versus chemotherapy or CRT alone

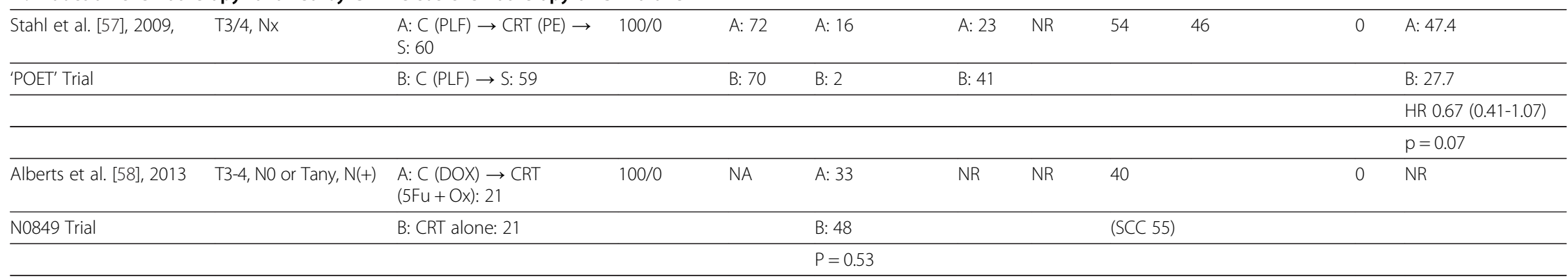

x. Adjuvant chemotherapy versus CRT

\begin{tabular}{|c|c|c|c|c|c|c|c|c|c|c|c|c|}
\hline Lee et al. [26], 2012 & II-IV & $A: S \rightarrow C(X P): 228$ & $100 / 0$ & NA & NA & A: 25 & A: 8.3 & 0 & 0 & 5 & 95 & A: 74.2 (3-year DFS) \\
\hline \multirow[t]{2}{*}{ 'ARTIST' Trial } & Any N+ & $\begin{array}{l}\text { B: } S \rightarrow C(X P) \rightarrow \\
C R T(X) \rightarrow C(X P): 230\end{array}$ & & & & B: 20 & B: 4.8 & & & & & B: 78.2 \\
\hline & & & & & & & $p=0.35$ & & & & & $p=0.086$ \\
\hline
\end{tabular}

* unless otherwise indicated.

Abbreviations: $A C$ adenocarcinoma; $S C C$ squamous cell carcinoma; $I T$ intention to treat; $p C R$ pathological complete response; $D R$ distant recurrence; $L R$ local recurrence; $E G J$ esophagogastric junction; $G C$ distal gastric

cancer; OS overall survival; $R T$ radiation therapy; CRT chemoradiotherapy; $P F$ cisplatin and 5-flourouracil; $N R$ not reported; $P F V$ cisplatin, 5 -flourouracil and vinblastine; $T P$ carboplatin and paclitaxel; $5 F U / L$ 5-flouroacil and

leucovorin; NA not applicable; HR hazard ratio; C chemotherapy alone; CF cisplatin and 5-flourouracil; CapeOx capecitabine and oxaliplatin; XP capecitabine and cisplatin; ECF epirubicin, cisplatin and 5-flourouracil;

PLF cisplatin, leucovorin and 5-flourouracil; PE cisplatin and etoposide; TXT docetaxel; CPT-11 Irinotecan; CDDP cisplatin. 
five weeks, with bolus 5 -FU ( $400 \mathrm{mg} / \mathrm{m} 2$ per day) and leucovorin $(20 \mathrm{mg} / \mathrm{m} 2$ per day) on the first four and the last three days of radiotherapy. One month after the completion of radiotherapy, two five-day cycles of 5-FU (bolus $425 \mathrm{mg} / \mathrm{m} 2$ per day) plus leucovorin $(20 \mathrm{mg} / \mathrm{m} 2$ per day) were given one month apart. The treatment completion rate was $64 \%$. The trial showed improvement in mOS of 36 versus 27 months (HR 0.76, CI 0.62-0.92, $\mathrm{p}=0.005$ ), 3 year DFS ( 50 vs. $41 \%$ ), and local recurrence rate (19 vs. $29 \%)$ with this adjuvant strategy. These data were recently updated and revealed a similar and persistent benefit, ensuring that adjuvant CRT with 5-FU remains a standard of care $[20,21]$. Of note, only $46 \%$ of the patients enrolled underwent $\geq$ D1 surgical resection (only 10\% D2) [19]. A subset analysis showed benefit in all subgroups except diffuse-type histology $[20,22]$. Caveats of this trial include the small number $(10 \%)$ of patients undergoing D2 resection (and even D1 only 36\%); it has been argued that the benefit gained by the addition of CRT merely offset the inadequate surgical approach (i.e. cleaning up a 'bad surgery'). However, a retrospective analysis by Kim et al. compared 544 patients all receiving D2 resection followed by CRT for GC, to 446 receiving D2 surgery alone at their institution [23]. They reported that both mOS (95.3 vs. 62.6 months, $\mathrm{p}=0.02$ ) and $\mathrm{mDFS}$ (75.6 vs. 52.7 months, $\mathrm{p}=0.0160)$ were significantly improved in the $\mathrm{S} \rightarrow \mathrm{CRT}$ group compared to surgery alone. A follow-up small phase III trial $(\mathrm{N}=90)$ of stage III/IV (TNM-6) patients suggested that the addition of radiation therapy to chemotherapy could improve the locoregional recurrence-free survival (LRRFS) but not disease-free survival of gastric cancer treated with R0 gastrectomy and D2 lymph node dissection; a subgroup analysis of only stage III disease did significantly prolong the 5-year LRRFS and disease free survival rates compared with chemotherapy $(93.2 \%$ vs $66.8 \%, \mathrm{p}=0.014 ; 73.5 \%$ vs $54.6 \%, \mathrm{p}=0.056$, respectively) [24]. In contrast, another study reported no difference in survival in their single institution observational cohort $(\mathrm{N}=142)$; a subgroup analysis of patients with $\mathrm{LN}+$ disease and higher $\mathrm{N}$-ratio trended to improved clinical outcomes [25]. The negative ARTIST trial, discussed below, sought to prospectively evaluate the benefit of adjuvant CRT compared to adjuvant chemotherapy alone, in patients having a D2 lymphadenectomy, and also suggested benefit only within the LN + subgroup [26].

\section{iii. Neoadjuvant chemotherapy $(\mathrm{C} \rightarrow \mathrm{S}$ ) vs. surgery alone}

There are two main randomized controlled trials in this group (that include AC) [27,28], of which only one trial was statistically significant [27]. Both trials included SCC and both used preoperative chemotherapy with cisplatin (Cis) and 5-fluorouracil (5-FU) - but with different dosing regimens and schedules: 2 cycles Cis- $80 \mathrm{mg} / \mathrm{m} 2,5 \mathrm{FU}$ $1000 \mathrm{mg} / \mathrm{m} 2$ days $1-4$ administered every three weeks
[27]; or Cis-50 mg/m2 D 1, 15, 29 and 5FU $2000 \mathrm{mg} / \mathrm{m} 2$ D1, 8, 15, 22, 29, 36 [28] - each followed by surgery and compared to surgery alone. The only positive trial was the OEO2 trial by the Medical Research Council (MRC) group, which randomized 871 patients (434 vs. 437), and enrolled $\sim 64 \%$ of patients with EGJ AC (10\% type III, $56 \%$ type I/II), the remainder being SCC of the esophagus. The HR for mOS was 0.78 (95\% CI 0.67-0.93) and showed a statistically significant 2 -year survival advantage with $43 \%$ versus $34 \%$ survival in favor of chemotherapy $(\mathrm{P}=0.004)$ [27], without reported interaction by histology. The recent long-term update of $\mathrm{OEO} 2$ confirmed the survival benefit with preoperative chemotherapy with HR $0.84(\mathrm{p}=0.03)$ and 5 -year rate of $23 \%$ vs. $17.1 \%$ [29]. However, the EORTC 40954 trial, which planned to enroll 360 patients in order to detect a HR of 0.71 with $80 \%$ power and 2sided significance level of $4 \%$, ultimately closed early due to poor accrual with only $40 \%$ of the intended patients (72 per arm). As might be expected, the HR for mOS and mPFS were not statistically different at 0.84 $(\mathrm{p}=0.466)$ and $0.76(\mathrm{p}=0.2)$, respectively [28].

Differences in treatment dosing, 'contamination' with SCC histology, under accrual (EORTC 40954) and conflicting results of these two trials leave an approach of neoadjuvant 5FU/Cisplatin chemotherapy alone without definitive evidence to refute or support its use. The metaanalyses discussed above, which included both neoadjuvant $\mathrm{CRT} \rightarrow \mathrm{S}$ and $\mathrm{C} \rightarrow \mathrm{S}$ trials, revealed survival benefit to chemotherapy alone [16,17]. In the first meta-analysis, the hazard ratio for neoadjuvant chemotherapy was 0.90 $(0.81-1.00 ; \mathrm{p}=0.05)$, with a 2 -year absolute survival benefit of $7 \%$. There was no significant effect on all-cause mortality of chemotherapy for patients with SCC (HR 0.88 [0.751.03]; $p=0.12$ ), although there was a significant benefit for those with adenocarcinoma (0.78 [0.64-0.95]; $\mathrm{p}=0.014$ ) [16]. The updated meta-analysis showed a HR for allcause mortality for all neoadjuvant chemotherapy patients (AC and SCC) of 0.87 [0.79-0.96; $\mathrm{p}=0.005$ ] [17]. The MRC OEO5 study is ongoing and evaluating two variables - a more aggressive triple drug regimen adding epirubicin (ECX) and for longer duration (4 cycles), versus CF (2 cycles) as in the OEO2 - results of which are awaited [30] (Table 2).

\section{iv. Adjuvant chemotherapy $(\mathrm{S} \rightarrow \mathrm{C})$ vs. surgery alone}

In the ACTS-GS trial from Japan, 1059 GC patients (50\% Stage II, 40\% Stage III AJCC 6 ${ }^{\text {th }}$ edition), who all underwent D2 dissection, were randomized to either observation or S-1 chemotherapy $(40 \mathrm{mg} / \mathrm{m} 2$ BID x 4 weeks, 2 weeks off) for 1 year [31,32]. Of note, $97 \%$ of patients had a T2 or T3 lesion and $90 \%$ of patients had N1 or N2 disease. There was a significant improvement in mOS with S-1 chemotherapy compared to observation that was maintained in the 5-year update with HR 0.67 (95\% CI 
Table 2 Ongoing phase II and III trials in locally advanced gastroesophageal adenocarcinoma

\begin{tabular}{|c|c|c|c|c|c|c|}
\hline Trial & Setting & $\mathrm{N}$ (To be enrolled) & Location & Primary endpoint & Intervention & Expected completion date \\
\hline Alderson et al. [30], 2013 & Neoadjuvant & 842 & Esophageal & Survival and QOL & $\mathrm{A}: \mathrm{C}(\mathrm{ECX} \times 4) \rightarrow \mathrm{S}$ & NR \\
\hline MRC OEO5 & & & EGJ I-II & & B: C (CF $\times 2) \rightarrow S$ & \\
\hline Kang et al. [35], 2013 & Adjuvant CRT & 1000 & Gastric and EGJ & DFS (3 years) & $A: S \rightarrow C(S 1)$ & January 2016 \\
\hline NCT01761461 & & & & & $\mathrm{B}: \mathrm{S} \rightarrow \mathrm{C}(\mathrm{S} 1 \times 1) \rightarrow \mathrm{CRT}(\mathrm{S} 1) \rightarrow \mathrm{C}(\mathrm{S} 1 \times 6)$ & \\
\hline \multirow[t]{2}{*}{ 'ARTIST II' } & & & & & $C: S \rightarrow C(S O X)$ & \\
\hline & & & & & $\mathrm{D}: \mathrm{S} \rightarrow \mathrm{C}(\mathrm{SOX}) \rightarrow \mathrm{CRT}(\mathrm{S} 1) \rightarrow \mathrm{C}(\mathrm{SOX} \times 4)$ & \\
\hline Lorenzen et al. [53], 2010 & Neoadjuvant CRT & NR & Resectable EGJ (I-II) & & Non-randomized, single institution & Not initiated \\
\hline NCT01271322 & & & & & A: C (Cisplatin/Taxotere) $\rightarrow$ PET & \\
\hline \multirow[t]{5}{*}{ 'HICON'Trial (Phase II) } & & & & & If Response: Continue C & \\
\hline & & & & & If No response: Cross to Arm B & \\
\hline & & & & & B: Taxane based CRT (45 Gy) $\rightarrow$ PET & \\
\hline & & & & & If Response: CRT (TP x 3) & \\
\hline & & & & & If No response: Cross to Arm A & \\
\hline Goodman et al. [54], 2013 & Neoadjuvant CRT & 204 & Esophageal and EGJ I and II & $\mathrm{pCR}$ & A: C (FOLFOX $\times 3) \rightarrow$ PET & September 2011 \\
\hline NCT01333033 & & & & & If Response: CRT (FOLFOX x 3) & \\
\hline \multirow[t]{4}{*}{ CALGB 80803 (Phase II) } & & & & & If No response: Cross to Arm B & \\
\hline & & & & & B: C (TP $\times 3) \rightarrow$ PET & \\
\hline & & & & & If Response: CRT (TP x 3) & \\
\hline & & & & & If No response: Cross to Arm A & \\
\hline Nordwest et al. [74], 2012 & Perioperative & 590 & Gastric EGJ I-III & DFS (2 years) & $\mathrm{A}: \mathrm{C}(\mathrm{FLOT} \times 4) \rightarrow \mathrm{S}(\mathrm{D} 2) \rightarrow \mathrm{C}(\mathrm{FLOT} \times 4)$ & July 2015 \\
\hline NCT01216644 & & & & & $\mathrm{B}: \mathrm{C}(\mathrm{ECF} \times 3) \rightarrow \mathrm{S}(\mathrm{D} 2) \rightarrow \mathrm{C}(\mathrm{ECF} \times 3)$ & \\
\hline \multicolumn{7}{|l|}{ 'FLOT4' } \\
\hline Chen et al. [72], 2012 & Perioperative & 722 & Gastric EGJ II or III & DFS (3 years) & $\mathrm{A}: \mathrm{C}(\mathrm{SOX}) \rightarrow \mathrm{S}(\mathrm{D} 2) \rightarrow \mathrm{C}(\mathrm{SOX})$ & September 2014 \\
\hline NCT01583361 & & & & & B: S (D2) $\rightarrow$ C (SOX) & \\
\hline \multicolumn{7}{|l|}{ 'RESONANCE' } \\
\hline Shen et al. [73], 2012 & Perioperative & 1059 & Gastric EGJ I-III & DFS (3 years) & $\mathrm{A}: \mathrm{S}(\mathrm{D} 2) \rightarrow \mathrm{C}(\mathrm{SOX} \times 8)$ & September 2014 \\
\hline \multirow[t]{2}{*}{ NCT01534546 } & & & & & B: S (D2) $\rightarrow$ C (XELOXX8) & \\
\hline & & & & & $\begin{array}{l}\mathrm{C}: \mathrm{C}(\mathrm{SOX} \times 3) \rightarrow \mathrm{S}(\mathrm{D} 2) \rightarrow \mathrm{C}(\mathrm{SOX} \times 5) \\
\rightarrow \mathrm{C}(\mathrm{S}-1 \times 3)\end{array}$ & \\
\hline Reynolds et al. [60], 2013 & Perioperative & 366 & Esophageal EGJ (I-III) & OS (3 years) & $A: C(E C F) \rightarrow S \rightarrow C$ (ECF) & September 2021 \\
\hline NCT01726452 & & & & & $\mathrm{B}: \mathrm{CRT}(\mathrm{TP}) \rightarrow \mathrm{S}$ & \\
\hline \multicolumn{7}{|l|}{ 'MAGIC vs. CROSS EGJ' } \\
\hline Verheji et al. [61], 2011 & Perioperative CRT & 788 & Gastric & OS & $\mathrm{A}: \mathrm{C}(\mathrm{ECC} \times 3) \rightarrow \mathrm{S}(\mathrm{D} 1+) \rightarrow \mathrm{CRT}(\mathrm{CC}, 45 \mathrm{~Gy})$ & June 2013 \\
\hline NCT00407186 CRITICS Trial & & & & & $\mathrm{B}: \mathrm{C}(\mathrm{ECC} \times 3) \rightarrow \mathrm{S}(\mathrm{D} 1+) \rightarrow \mathrm{C}(\mathrm{ECC} \times 3)$ & \\
\hline
\end{tabular}


Table 2 Ongoing phase II and III trials in locally advanced gastroesophageal adenocarcinoma (Continued)

\begin{tabular}{|c|c|c|c|c|c|c|}
\hline Leong et al. [62], 2013 & Peri-operative CRT & 752 & Gastric EGJ & OS & $\begin{array}{l}\text { A: } C(E C F / X \times 2) \rightarrow C R T(5-F U / R T) \rightarrow S \\
\rightarrow C(E C F / X \times 3)\end{array}$ & NR \\
\hline 'TOP GEAR' (Australia) & & & & & B: C (ECF/X×3) $\rightarrow S \rightarrow C(E C F / X \times 3)$ & \\
\hline \multicolumn{7}{|c|}{ Molecularly targeted trials } \\
\hline Safran et al. [67], 2013 & Neoadjuvant CRT & 480 & $\begin{array}{l}\text { Mid and Distal Esophagus } \\
\text { including EGJ }\end{array}$ & DFS & $\mathrm{A}: \mathrm{CRT}(\mathrm{TP}) \rightarrow \mathrm{S} \rightarrow \mathrm{T}(13)$ & August 2018 \\
\hline NCT01196390 & & & & & $\mathrm{B}: \mathrm{CRT}(\mathrm{TP}) \rightarrow \mathrm{S}$ & \\
\hline \multicolumn{7}{|l|}{ RTOG 1010} \\
\hline Reed et al. [68], 2012 & Neoadjuvant CRT & 69 & Distal Esophagus and EGJ & $\mathrm{pCR}$ & $\mathrm{CRT}(\mathrm{CDP}) \rightarrow \mathrm{S}$ & Study Completed \\
\hline \multicolumn{7}{|l|}{ NCT00757172 } \\
\hline \multicolumn{7}{|l|}{ ACASOG Z4051 } \\
\hline \multicolumn{7}{|l|}{ Phase II } \\
\hline Ilson et al. [69], 2012 & Neoadjuvant CRT & 420 & $\begin{array}{l}\text { Esophageal (Squamous allowed) } \\
\text { GEJ I-II }\end{array}$ & OS & A: CRT (CCT, $50.4 \mathrm{~Gy})$ & August 2018 \\
\hline NCT00655876 & & & & & B: CRT (CT, 50.4 Gy) & $\begin{array}{l}\text {-Closed at interim analysis } \\
\text { for AC arm due to low } \\
\text { clinical complete response }\end{array}$ \\
\hline RTOG 0436 & & & & & & $\begin{array}{l}\text {-Closed SCC arm due to } \\
\text { SCOPE-1 results (see text) }\end{array}$ \\
\hline $\begin{array}{l}\text { Cunningham et al. [75], } \\
2012\end{array}$ & Perioperative & 1100 & Gastric EGJ I-III & OS, Safety, Efficacy & $\mathrm{A}: \mathrm{C}(\mathrm{ECXB}) \rightarrow \mathrm{S} \rightarrow \mathrm{C}(\mathrm{ECXB})$ & December 2014 \\
\hline \multicolumn{7}{|l|}{ NCT00450203 } \\
\hline 'MAGIC-B' (ST03) & & & & & $\mathrm{B}: \mathrm{C}(\mathrm{ECX}) \rightarrow \mathrm{S} \rightarrow \mathrm{C}(\mathrm{ECX})$ & \\
\hline
\end{tabular}

Abbreviations: PET positron emission tomography; FLOT 5-flourouracil, leucovorin, oxaliplatin and docetaxel; FOLFOX 5-FU, leucovorin and oxaliplatin; XELOX oxaliplatin with capecitabine; ECC epirubicin, cisplatin, capecitabine; CDP cisplatin, docetaxel, panitumumab; CCT cetuximab, cisplatin, and paclitaxel; SOX S-1 and oxaliplatin; TP paclitaxel and carboplatin; $T$ trastuzumab; $B$ bevacizumab; QOL Quality of Life; 5-FU/L 5-flouroacil and leucovorin; $R T$ radiation therapy; XP/RT capecitabine/cisplatin/radiotherapy; NR not reported. 
0.54-0.828) and 5-yr DFS 71.7\% vs 61.1\%, respectively. The authors concluded that $\mathrm{S}-1$ is an effective adjuvant treatment after D2 dissection in East Asian patients with locally advanced GC [31,32].

Paoletti et al. conducted a large metaanalysis of 17 RCTs with individual patient data for 3838 patients to evaluate the efficacy of adjuvant chemotherapy (heterogeneous regimens) compared to surgery alone. They reported an absolute 5- year overall survival advantage of $5.7 \%$ with adjuvant chemotherapy compared to surgery alone (55.3 vs. $49.6 \%$ respectively, HR 0.82, CI 0.76-0.90, $\mathrm{P}=0.001)$ with similar HR for DFS [33].

Recently, the 'CLASSIC' trial was reported by Bang et al. in stage II-IIIB GC patients [34]. All patients underwent curative D2 gastrectomy and were enrolled from 37 centres in South Korea, China, and Taiwan. Patients were randomized to either observation or adjuvant chemotherapy with 8 cycles of CapeOx (oral capecitabine, $1000 \mathrm{mg} / \mathrm{m} 2 \mathrm{BID}$ on D 1-14 of each 3 week cycle, plus oxaliplatin $130 \mathrm{mg} / \mathrm{m} 2$ on D1 of each 3 week cycle) for 6 months. The trial showed significant improvement in the 3 -yr OS $(83 \%$ vs. $78 \%$, HR $0.72,95 \%$ CI 0.62-1; $\mathrm{p}=0.0493$ ) and 3-yr DFS with adjuvant CapeOx compared to surgery alone (74 vs. $59 \%$, HR 0.56 , 95\% CI 0.44-0.72; $\mathrm{p}<0$-0001); mature data for robust estimates of mOS are awaited. The adjuvant chemotherapy was associated with more grade $\geq 3$ toxicity compared to surgery alone ( $56 \%$ vs. $6 \%$ respectively) with nausea, neutropenia, and decreased appetite as the major toxicities [34]. The four arm 'ARTIST-II' trial, assesses S1 monotherapy versus S1 and oxaliplatin (SOX) with or without CRT (with concurrent S1) in LN + disease only [35] (Table 2).

\section{v. Perioperative 'sandwich' chemotherapy $(\mathrm{C} \rightarrow \mathrm{S} \rightarrow \mathrm{C})$ vs. surgery alone}

The trial, INT-0113/RTOG8911, by Kelsen et al. randomized 467 patients $(53 \% \mathrm{AC})$ to surgery alone or to 3 monthly preoperative cycles and 2 post-operative cycles of Cisplatin $100 \mathrm{mg} / \mathrm{m} 2$ and 5FU $1000 \mathrm{mg} / \mathrm{m} 2$ days $1-5$ $[36,37]$. This resulted in no difference in survival $(\mathrm{p}=0.53)$ [36], yet updated results revealed that patients who responded to chemotherapy radiographically $(n=39,19 \%$ total, $12 \% \mathrm{PR}, 7 \% \mathrm{CR}$ ) had a substantial improvement in long term survival, while the non-responders did not differ significantly from those undergoing surgery alone, a phenomenon that was similar to the MUNICON studies discussed below. Moreover, R0 resection proved to be a major determinant of long-term survival, and the chemotherapy (ITT) group had a R0 rate of $63 \%$ versus $59 \%$ (ITT) [36,37]. Of note, in multivariate analysis, for patients assigned to chemotherapy and surgery, not responding to chemotherapy ( $\mathrm{HR}, 2.83 ; 95 \% \mathrm{CI}, 1.84$ to 4.35; $\mathrm{p}<0.0001)$ and $>10 \%$ weight loss $(\mathrm{HR}, 1.47$; $95 \% \mathrm{CI}$, 1.09 to $1.98 ; \mathrm{p}=0.0109)$ were associated with increased risk of death, while adenocarcinoma histology (HR, 0.59;
95\% CI, 0.44 to 0.80 ) was associated with decreased risk of death. Only $70 \%$ of patients received all three cycles of preoperative therapy, and only $30 \%$ of patients received at least one post-operative cycle [36,37].

In contrast, two large randomized controlled trials, 'MAGIC' and the FNLCC ACCORD07-FFCD9703 trial, established the role of perioperative chemotherapy in improving survival compared to surgery alone [38,39]. Both of these trials included only patients with AC histology, with $\sim 25 \%$ and $75 \%$ EGJ tumors in 'MAGIC' and FFCD trials, respectively.

The 'MAGIC' trial enrolled 503 patients randomizing to 3 cycles of ECF before and 3 cycles after surgery, compared to surgery alone. This resulted in an improvement in mOS with HR $0.75(95 \%$ CI $0.60-0.93, \mathrm{p}=0.009)$ and 5 -yr survival rate of $36 \%$ versus $23 \%$ compared to surgery alone. There was a similar benefit in PFS with HR 0.66 (95\% CI $0.53-0.81, \mathrm{p}<0.001)$. Only $66 \%$ of the patients started postoperative chemotherapy and $76 \%$ of these patients actually completed the planned course of chemotherapy; only $41.6 \%$ of patients completed all 6 cycles of therapy. This is a significantly higher completion rate than in the INT-0113 trial, discussed above [36,37]. There was a significant trend to having fewer patients in the advanced T-stage $(\mathrm{p}=0.002)$ and $\mathrm{N}+$ groups $(\mathrm{p}=0.01)$ within the perioperative chemotherapy group, despite randomization. Only $41 \%$ of patients received a D2 resection, (D1 19\%, D0 40\%). R0 resection was observed in $79 \%$ versus $69 \%$ of patients in favor of the chemotherapy arm (ie. not ITT). It should be noted that 91.6\% of patients in the $\mathrm{C} \rightarrow \mathrm{S} \rightarrow \mathrm{C}$ arm underwent surgery, while $96.4 \%$ underwent surgery in the control arm. More patients did not proceed to surgery in the chemotherapy arm (6.1\%) versus the surgery alone arm (2.4\%), many of which progressed during the neoadjuvant chemotherapy phase, thus excluding them from curative-intent surgery. It can be argued that this neoadjuvant approach delaying immediate resection actually spared this subset of patients with aggressive disease from unnecessary surgery, which would have unlikely changed the ultimate outcome.

The ACCORD07 trial randomized patients to cisplatin $(100 \mathrm{mg} / \mathrm{m} 2)$ and $5 \mathrm{FU}(800 \mathrm{mg} / \mathrm{m} 2 \mathrm{D} 1-5)$ every 28 days $(\mathrm{N}=113)$ for up to 3 cycles prior to surgery and up to 4 cycles after surgery, versus surgery alone $(\mathrm{N}=111)$ (D2 recommended) [39]. The trial slightly underaccrued from its target enrollment of 250 patients. Most patients in the chemotherapy arm received 2 cycles preoperatively (78\%), and $87 \%$ of patients received at least 2 preoperative cycles. Among those who received at least 1 cycle of preoperative chemotherapy $(\mathrm{n}=109), 54$ patients $(50 \%)$ received at least 1 cycle of post-operative therapy (6/7/16/25 patients received $1 / 2 / 3 / 4$ cycles postoperatively, respectively). Of those who relapsed (55\% vs. $64 \%$ ), locoregional only relapse was low (12 vs. $8 \%$ in the chemotherapy vs. surgery alone, respectively), compared to the aggregate of distant relapse 
and both distant/local relapse (42\% for chemotherapy, 56\% for surgery alone). This emphasized the systemic nature of GEC. The mOS was improved with HR 0.69 (95\% CI 0.50$0.95, \mathrm{p}=0.02$ ) with 5 -yr survival rates of $38 \%$ vs. $24 \%$. DFS similarly was improved with HR 0.65 (95\% CI 0.48-0.89, $\mathrm{p}=0.003$ ) with 5 -yr DFS rates of $34 \%$ vs. $19 \%$. R0 resection rate was observed in $84 \%$ vs. $74 \%$ of patients. The subgroup analysis of EGJ patients (comprising 75\% of accrued patients) for mOS, revealed a HR 0.57 (95\% CI 0.39-0.83). Caveats to both the 'MAGIC' and 'ACCORD07 ' trials were lack of pre-treatement staging as endoscopic ultrasound was as yet unavailable. Given very similar results between 'MAGIC' and 'ACCORD-07', the additional benefit of epirubicin in this setting has been questioned, which may be potentially addressed in the ongoing OEO5 trial (without a post-operative chemotherapy component), discussed above.

Interestingly, phase II reports with FLOT and DCF 'sandwich' chemotherapy have reported $\mathrm{pCR}$ rates of $10-12 \%$, and R0 rates ranging $\sim 85-100 \%$, supporting the ongoing evaluation of these regimens in larger trials [40-42] (Table 2).

With similar survival benefits as measured by HR and absolute 5-year survival rates of the 'sandwich' approach to neoadjuvant CRT for EGJ AC, perioperative treatment with ECF or CF are accepted standards, particularly in Britain, Europe and some centers in North America.

\section{vi. Comparison of post-operative chemotherapy regimens $S \rightarrow$ FOLFIRI then DC vs $S \rightarrow 5 F U$}

The ITACA-S trial evaluated whether intensification of postoperative chemotherapy would improve outcomes of patients undergoing curative intent resection of GC or EGJ AC. Patients with $\geq D 1$-lymphadenectomy were randomized to irinotecan $180 \mathrm{mg} / \mathrm{m}^{2}$ on d1, LV $100 \mathrm{mg} / \mathrm{m} 2 \mathrm{~d} 1-2$, 5-FU 400-600 mg/m2 d1-2, q14; (FOLFIRI regimen) for 4 cycles, followed by docetaxel $75 \mathrm{mg} / \mathrm{m} 2 \mathrm{~d} 1$, cisplatin $75 \mathrm{mg} / \mathrm{m} 2 \mathrm{~d} 1$, q 21; (DC regimen) for 3 cycles (arm A) as compared to the 'control' arm of LV $100 \mathrm{mg} / \mathrm{m} 2 \mathrm{~d} 1-2$, 5-FU 400-600 mg/m2 d1-2, q 14 for 9 cycles (arm B). Patients were randomized ( $562 \mathrm{arm} \mathrm{A,} 538 \mathrm{arm} \mathrm{B}$ ) by 123 Italian centers. The primary endpoint of DFS was not statistically different between the groups (HR 0.98; 95\% CI $0.83-1.16 ; \mathrm{p}=0.83$ ), nor was there an observed difference in $\mathrm{mOS}$ (HR 1.00; 95\% CI 0.83-1.20; $\mathrm{p}=0.98$ ). The authors concluded that adjuvant chemotherapy for GC/EGJ with a more intensive regimen did not result in a significant prolongation of DFS and OS when compared to the bolus/ infusion FU/LV regimen, suggesting that intensification of chemotherapy may not improve outcomes [43].

\section{$(\mathrm{S} \rightarrow U F T$ vs $S \rightarrow S 1$ vs $S \rightarrow$ paclitaxel then UFT vs. $S \rightarrow$ paclitaxel then $S 1$ )}

The four arm SAMIT trial was a phase III trial with a two-by-two factorial design planned to assess the survival benefit of adjuvant chemotherapy intensificaiton via sequential use of paclitaxel and oral flurinated pyrimides (FP) in comparison to FP alone, and to compare the FPs tegafur/uracil (UFT) versus S-1. An initial report showed that adjuvant chemotherapy with various combinations of taxol and fluoropyrimindines was well tolerated [44]. Recently, the final results were reported, where the primary endpoint of DFS revealed that UFT was inferior to S-1 (HR 1.23, 1.07-1.43), and that there was a nonsignificant trend (HR 0.92, 0.8-1.07; $\mathrm{p}=0.23$ ) to improved DFS with sequential PTX $\rightarrow$ FP versus FP alone [45].

These two trials, SAMIT and ITACA-S, suggest that intensification of chemotherapy does not improve survival over fluoropyrimidine alone.

\section{vii. Adjuvant CRT comparing peri-RT chemotherapy regimens \\ $(S \rightarrow 5 F U-C R T-5 F U$ vs $S \rightarrow$ ECF-CRT-ECF)}

The CALGB 80101 trial by Fuchs et al. compared postoperative CRT with intensified peri-RT chemotherapy using ECF versus the standard 5FU treatment [46]. However, the control arm received a modified 'Macdonald regimen', with continuous infusion $(\mathrm{CI}) 5 \mathrm{FU} 200 \mathrm{mg} / \mathrm{m} 2$ everyday through to completion of radiation (45Gy), rather than the original bolus 5FU concurrently with RT. The investigational arm received 1 cycle of ECF chemotherapy before and 2 cycles ECF after CRT, in 546 patients with GC or EGJ AC ( 33\%). The trial did not show any significant difference between the ECF and 5-FU arms for mOS (HR, 1.03; 95\% CI, 0.80-1.34; $\mathrm{p}=0.8$ ) or 3-yr DFS (52 vs. $50 \%$ respectively). Counter-intuitively, the toxicity comparison between the 5-FU arm compared to the ECF arm revealed a slightly higher treatment related mortality (3\% vs. $<1 \%$ respectively) as well as grade 4 toxicity ( $40 \%$ vs. $26 \%$ respectively, $\mathrm{p}<0.001$ ); this may be attributed to the different peri-RT chemotherapy dose schedules of the $5 \mathrm{FU}$ between the arms (bolus 'Macdonald regimen' versus continuous infusion). The authors concluded that there is no survival advantage of postoperative CRT using intensified peri-RT ECF compared to 5-FU [46]. The authors also indicated that there was an approximate 40\% D2 resection rate, but that accurate D0/D1/D2 resection rates will be reported at a later date [46].

\section{viii. PET directed therapy}

Sarkaria et al. conducted a retrospective study using a prospectively maintained database to determine if endoscopic biopsy after neoadjuvant CRT therapy would predict pathological CR (pCR) [47]. It was observed that a negative endoscopic biopsy was not reliable for predicting pCR, nodal stage or overall survival. Overall, PET imaging for predicting pathologic response in EGJ has been most promising. In a retrospective study, Weber and colleagues first established that a SUV decrease of $\geq 35 \%$ from baseline 
was predictive of 2-year survival with a sensitivity of $93 \%$ and specificity of 95\% [48]. The SUV cut-off was subsequently validated prospectively by Ott et al. [49]. They also found that metabolic responders showed a high histopathologic response rate of $44 \%$ compared to only $5 \%$ in metabolic non-responders $(p=0.001)$ [49]. This led to a single center, exploratory, phase II 'MUNICON' study in patients with EGJ cancer [50]. Enrolled patients ( $\mathrm{N}=119 \mathrm{EGJ} \mathrm{I} / \mathrm{II})$ were originally staged as cT3 or cT4 based on CT, EUS, and PET. A repeat PET scan at day day 14 into treatment, as compared to baseline, was done to assess the metabolic response to chemotherapy (cisplatin and 5-FU). Responders continued with chemotherapy for 12 weeks, while non-responders proceeded directly to surgery. In metabolic non-responders, mOS was 25.8 months (19.432.2), whereas mOS was not reached in responders after a follow-up of 2.3 years (HR 2.13, CI 1.14-3.99, p =0.015). A major histological remission $(<10 \%$ residual tumor) was found in $58 \%$ of metabolic responders, compared to none in metabolic non-responders. R0 resection rates were $82 \%$ in PET-responders, and $70 \%$ in non-responders. Importantly, a comparison of these observed results to historic cohorts showed that discontinuing inactive chemotherapy after 2 weeks, and avoiding delay in surgery, did not adversely affect outcomes [51]. Based on these results, the 'EUROCON' trial planned to randomize metabolic nonresponders after 2 weeks of chemotherapy to immediate resection or CRT followed by surgery, but this trial did not materialize. However, the smaller 'MUNICON-II' trial was completed $(\mathrm{N}=56$, EGJ I/II) where PET-responders were continued on chemotherapy alone (cisplatin $50 \mathrm{mg} / \mathrm{m} 2$ days 1,15 , and $29 ; 5 \mathrm{FU} 2000 \mathrm{mg} / \mathrm{m} 2$ over 24 hours days 1,8 , $15,22,29$, repeated on day 49 ; folinic acid $500 \mathrm{mg} / \mathrm{m} 2$ over 2 hours with each 5FU administration), while nonresponders proceeded with neoadjuvant CRT prior to surgery [52]. This design had the power to detect an improvement in the R0 resection rate from $74 \%$ to $94 \%$ in non-responders (1-sided alpha 0.1 , power 0.8 ), with requirement of treating 23 non-responders with salvage neoadjuvant CRT (32 Gy with 1.6 Gy twice daily and 10 fractions per week; cisplatin $6 \mathrm{mg} / \mathrm{m} 2$ days $1-5$ and $8-12$ OR $5 \mathrm{FU} 250 \mathrm{mg} / \mathrm{m} 2 \mathrm{CI}$ if renal function inadequate). Of the 56 patients enrolled, 23 were non-responders and obtained 'salvage' CRT prior to surgery. The 2-year survival rates were $74 \%$ vs $57 \%(\mathrm{p}=0.035)$ in favor of the PET-responders. Although there was an increased histopathological response observed in the 'MUNICON-II' salvage CRT non-responder group (as compared to the 'MUNICON I' trial histopathological rate, where nonresponders proceeded directly to surgery without further neoadjuvant treatment), the primary endpoint was not reached in 'MUNICON-II' with an observed R0 resection rate of $74 \%$, not significantly better than the R0 rate of $70 \%$ observed in 'MUNICON-I'. 'MUNICON-II' confirmed the poor prognosis of PET non-responders (which is approximately $50-60 \%$ of EGJ I/II patients), despite aggressive salvage neoadjuvant CRT. The authors concluded that despite salvage neoadjuvant CRT in PETnonresponders leading to local remissions in $6(16 \%)$ of patients, it was not able to change the clinical course in general because of the systemic disease recurrence patterns. They also surmised that improvement of distant recurrence would be required to improve outcomes for this patient subset. Criticism of the MUNICON-II trial is the relatively low dose of radiation, as well as the single agent Cisplatin (or 5FU) during CRT, which is less aggressive than desired for optimal local control.

In addition to the "MUNICON-I and -II" trials, the 'HICON' and CALGB 80803 clinical trials plan to evaluate PET-directed treatment in the neoadjuvant setting prior to surgery for EGJ, as discussed below [53-55]. Unfortunately, the HICON trial was never initiated. Moreover, PET directed therapy is being evaluated for locally advanced GC where patients with baseline PET tumor SUV $>3.5$ (or tumor : liver ratio $>1.5$ ) receive one cycle (C1) epirubicin $(50 \mathrm{mg} / \mathrm{m} 2)$, cisplatin $(60 \mathrm{mg} / \mathrm{m} 2)$ day and capecitabine $(625 \mathrm{mg} / \mathrm{m} 2$ twice daily days 1-21) (ECX) with bevacizumab ( $15 \mathrm{mg} / \mathrm{kg}$ day 1 ) therapy preoperatively for 21 days, with a repeat post-C1 PET. Patients with a metabolic response ( $>35 \%$ decrease in FDG uptake) on repeat PET proceed with two further cycles of the initial treatment. PET nonresponders switch to 'salvage' docetaxel $(30 \mathrm{mg} / \mathrm{m} 2)$ and irinotecan $(50 \mathrm{mg} / \mathrm{m} 2)$ Days 1 and 8 every 3 weeks, along with bevacizumab (15 mg/kg day 1$)$, for two cycles. Postoperatively, patients continue on the chemotherapy regimen they received just prior to surgery for three more cycles [56]. Twenty of 60 planned patients were enrolled before closure of this trial to poor accrual; 11/20 had PET response. Ten of 11 (91\%) responders achieved R0 resection and 4/11 (36\%) achieved pathological responses (1 pCR, 3 pPR). Seven of 9 (77\%) PET non-responders achieved R0 resection; none achieved a pathological response. There was no significant difference in DFS between the responders and non-responders $(p=0.4)$. This hypothesis generating pilot trial demonstrated that PET imaging during induction chemotherapy can identify early treatment failures, with potential benefit of altering to salvage chemotherapy. This has led to the proposal of a larger Cooperative Group trial currently under consideration.

\section{ix. Induction chemotherapy followed by chemoradiation $(C \rightarrow C R T \rightarrow S$ vs. $C \rightarrow S ; C \rightarrow C R T \rightarrow S$ vs. $C R T \rightarrow S$ )}

One reported trial, 'POET', assessed the benefit of induction chemotherapy followed by concomitant CRT in randomized fashion versus chemotherapy alone, (unlike 'MUNICON-II', discussed above, where only PET-nonresponders of 'induction' chemotherapy proceeded with 
CRT) [50]. The 'POET' trial, used induction chemotherapy with PLF (cisplatin, leucovorin and 5-fluorouracil), comprised of cisplatin $50 \mathrm{mg} / \mathrm{m} 2$ biweekly and weekly $5 \mathrm{FU}$ $2000 \mathrm{mg} / \mathrm{m} 2$ with leucovorin (one course 6 weeks) [57]. The investigational arm completed 2 courses of PLF followed by RT with concurrent PE (cisplatin $50 \mathrm{mg} / \mathrm{m} 2 \mathrm{D}$ 1,8 and etoposide $80 \mathrm{mg} / \mathrm{m} 2 /$ day D 3-5) compared to the 'control arm' of chemotherapy alone using PLF for 2.5 courses (15 weeks) followed by surgery. This trial, then, was comparing neoadjuvant chemotherapy with/without CRT prior to surgery. Unique inclusion criteria included only high-risk T3-4 patients with EGJ AC (Siewert's I-III). The trial required pre-operative staging with EUS and laparoscopy. Unfortunately, the accrual goal was not met (only 33\% of the planned patients were recruited, $\mathrm{N}=119$ ). The trial showed a trend towards improvement in 3 year OS with induction chemotherapy followed by CRT (47 vs. $28 \%$, respectively) but it was not statistically significant (HR 0.67, CI 0.41-1.07, $\mathrm{p}=0.07$ ). Additionally, the $\mathrm{pCR}$ rates (16 vs. $2 \%$ ) and local control (77 vs. $59 \%$ ) were better in the investigational CRT arm compared to the chemotherapy alone control [57]. The comparison of induction chemotherapy prior to CRT versus chemotherapy alone seemed promising in this trial, albeit using an unconventional chemotherapy of etoposide during RT. However, from the 'MUNICON-II' trial (with recognized caveats of potentially underdosed RT and inadequate concurrent chemotherapy with cisplatin alone), it appeared that nonresponders to chemotherapy alone did not derive large therapeutic benefit from further neoadjuvant CRT in terms of survival or R0 resection rates, while chemotherapy responders had improved outcomes. Therefore, it is possible that chemotherapy responders may be treated optimally with chemotherapy alone, without deriving benefit from additional CRT. To prospectively study this, a trial exclusively evaluating chemotherapy responders randomized to continued chemotherapy versus intensified CRT could be done, in order to determine if CRT adds anything to those already responding to chemotherapy alone. Similarly, to evaluate the utility of induction chemotherapy prior to CRT (assuming the need for CRT), a prospective randomized trial of induction chemotherapy prior to CRT versus CRT alone would be required. One such trial, N0849, was recently reported, with the primary endpoint assessing pCR rate [58]. The interim report on efficacy and futility revealed a pCR rate of $7 / 21(33 \%)$ in the induction chemotherapy arm versus 10/21 (48\%) in the CRT alone arm, and R0 resection rates of 16/17 (94\%) versus 20/20 (100\%), respectively. The authors concluded the induction chemotherapy failed to improve $\mathrm{pCR}$ rates, yet followup in regard to survival and rate (and site) of recurrence is ongoing [58]. One might suggest that addition of induction chemotherapy would not be expected to improve $\mathrm{pCR}$ rates, but rather and if anything, decrease distant recurrence rates - data which are currently not mature. Regardless, the principle of $\mathrm{C} \rightarrow \mathrm{CRT}$ prior to surgery for all patients, whether there is response or not to the induction chemotherapy, is being evaluated in CALGB 80803 trial using a PET directed algorithm with chemotherapy backbone cross-over if there is demonstrated lack of PET response - intentions of optimizing both local (RT) and distant (chemotherapy) control [54] (Table 2).

\section{x. Adjuvant chemotherapy versus CRT \\ $(\mathrm{S} \rightarrow \mathrm{C}$ vs. $\mathrm{S} \rightarrow$ C-CRT-C)}

In addition to the small trial by Kim et al. above [24], Lee et al. treated 458 resected GC patients with postoperative chemotherapy in the 'ARTIST' trial, with 2 cycles of XP (capecitabine and cisplatin), followed by concurrent capecitabine with RT, followed by 2 more cycles of XP, compared to post-operative chemotherapy consisting of 6 cycles of XP alone [26]. Again, all patients underwent D2 gastrectomy and had R0 resection of GC (only 5\% type III EGJ). The primary endpoint of the trial, DFS, was not met with 3-yr DFS rates available at the time of reporting (78.2\% vs. $74.2 \% ; \mathrm{P}=0.0862$ ). However, a subgroup analysis of $\mathrm{LN}+$ disease $(\mathrm{N}=396,86 \%)$ did reveal improved DFS with HR 0.6865 (95\% CI 0.47-0.99; $\mathrm{P}=0.047$ ) [26]. The authors, due to the nature of subgroup analyses, caution regarding conclusions with respect to $\mathrm{LN}+$ disease, and indicate that a subsequent trial, 'ARTIST-II', will prospectively evaluate the utility of $\mathrm{C} \rightarrow \mathrm{CRT} \rightarrow \mathrm{C}$ versus chemotherapy alone ( $\mathrm{S} 1$ versus $\mathrm{S} 1$ and oxaliplatin - SOX) in $\mathrm{LN}+$ disease undergoing D2 resection in a four-arm trial [35]. The 'ARTIST-II' trial will evaluate the question of intensification in LN + only disease. The results from 'ARTIST' suggest that low-stage $(\mathrm{N}-)$ disease may be adequately treated with modified D2 resection without the need for CRT.

\section{The devil is in the details: which perioperative approach?}

Adding the recent trials 'CROSS', CALGB 80101, 'CLASSIC', 'ITACA-S', ACCORD07 and 'ARTIST' to the repertoire of pre-2010 studies evaluating various perioperative treatment strategies, no regimen has emerged with international consensus for GC or EGJ AC cancers. Excluding the 'ITACA-S', SAMIT, 'ARTIST', CALGB80101, and 'POET' trials, all of the discussed relevant stand-alone phase III trials compare the investigational arm to surgery alone, making direct comparison of differing perioperative approaches complicated. We are limited to cross-trial comparisons and meta-analyses, and the caveats and shortcomings that this entails, including differences in enrollment criteria and actual enrollment variances, such as tumor location (i.e. GC/EGJ mix) (Figure 1). For instance, EGJ AC tumors are less-well represented within $\mathrm{S} \rightarrow \mathrm{CRT}$ and $\mathrm{S} \rightarrow \mathrm{C}$ trials, whereas they do comprise a more substantial subset within $\mathrm{C} \rightarrow \mathrm{S} \rightarrow \mathrm{C}, \quad \mathrm{C} \rightarrow \mathrm{CRT} \rightarrow \mathrm{S}$, and $\mathrm{CRT} \rightarrow \mathrm{S}$ trials. 
Additionally, differences in histology (ie AC +/- SCC), stage (eg. most enrolled $\geq$ stage II, but some enrolled $\geq$ stage Ib; whether EUS and/or staging laparoscopy/washings were performed), and other nuances such as proportion of D1/D2 surgery, chemotherapy and radiotherapy type, dose and/or schedule, and geographic location/ethnic makeup variances from trial to trial, all make cross-trial comparisons quite problematic.

While there is consensus that 'something-other-thansurgery-alone' should be done for GEC, and in particular EGJ AC, with consistent clinical improvement observed regardless of the perioperative approach chosen $(\sim 10-15 \%$ absolute 5-yr survival benefit, HR 0.60-0.80), opinions regarding $\mathrm{C} \rightarrow \mathrm{S} \rightarrow \mathrm{C}$ vs $\mathrm{CRT} \rightarrow \mathrm{S}$ differ, and are formulated based on cross-trial comparisons and clinician experiences. For patients seeking second/third opinions, this can be particularly confusing when they receive different opinions regarding treatment strategy. The 'CROSS' authors favor $\mathrm{CRT} \rightarrow \mathrm{S}$ for EGJ AC, stating that the 'ACCORD-07' and 'MAGIC' trials have a heterogeneous distribution of GC and EGJ patients, as well as citing the under-accrued relatively small 'POET' trial as supporting arguments [18]. However, the 'POET' trial was not a comparison of $\mathrm{C} \rightarrow \mathrm{S} \rightarrow \mathrm{C}$ to $\mathrm{CRT} \rightarrow \mathrm{S}$, but rather $\mathrm{C} \rightarrow \mathrm{S}$ to $\mathrm{C} \rightarrow \mathrm{CRT} \rightarrow \mathrm{S}$, and had unique T-stage eligibility (Table 1 ), used non-standard CRT with etoposide, under-accrued, and ultimately, had a non-significant survival difference. Moreover, 'ACCORD07' accrued 75\% EGJ patients, and subset survival analysis of these EGJ patients showed a HR 0.57 (0.39 to 0.83), albeit without statistically significant interaction by tumor location, possibly due to lack of power of this analysis. Furthermore, the 'CROSS' trial also had significant differences in eligibility, namely, histology (SCC 25\%); despite the statement that benefit was consistent across histologic subgroups without interaction, the AC patients clearly demonstrated less benefit in terms of $\mathrm{pCR}$, recurrence, and survival (HR 0.74 (0.53-1.02)). Finally, as demonstrated by the relapse patterns of the 'ACCORD07' and 'MUNICON' trials, distant recurrence is the apparent challenge for EGJ $\mathrm{AC}$, for all patients, whether treated with chemotherapy, CRT or surgery alone, underscoring the systemic nature of EGJ AC. Until superior approaches are available that diminish distant recurrence, local control will be less important in terms of survival benefit, in contrast to the SCC histology. An important exception includes the scenario when R0 resection is deemed unattainable without RT prior to surgery. Again, although the $\mathrm{pCR}$ rate with neoadjuvant chemotherapy alone is low, ranging from 2$7 \%[36,38,39,57]$, these lower pCR rates, as compared to CRT (20-25\%), appear to be less important than R0 resections in predicting long-term survival. With chemotherapy alone, absolute R0 rates are improved over surgery alone approximately 10\% (eg. ACCORD 07: 74\% to $84 \%$, MAGIC $69 \%$ to $79 \%$ ). Despite these rates being lower than those of $\mathrm{CRT} \rightarrow \mathrm{S}$ in some trials (CROSS 68 to $90 \%$ for AC) compared to surgery alone, the HR and absolute 5-year survival rates are similar between the two strategies. In contrast, R0 resections rates were not significantly different in the POET trial comparing $\mathrm{C} \rightarrow \mathrm{S}$ to $\mathrm{C} \rightarrow \mathrm{CRT} \rightarrow \mathrm{S}$ (70 vs $72 \%$, respectively; Table 1 ) [57]. However, if RT is determined to be required to optimize R0 resection at multi-disciplinary tumor board, such as with T4 tumors, then it is appropriate to proceed accordingly [59]. Therefore, in general, higher pCR and even R0 resections seen with neoadjuvant CRT do not correlate with long-term overall survival improvement in comparison to 'sandwich' chemotherapy strategies (with the limitations of cross-trial comparisons). This is likely a function of the systemic propensity of GEC and ultimate distant recurrence. Moreover, as discussed above in PET-directed therapy, the MUNICON II trial may provide an explanation for the apparent lack of significant survival differences between the CRT $\rightarrow \mathrm{S}$ and $\mathrm{C} \rightarrow \mathrm{S} \rightarrow \mathrm{C}$ strategies. It is plausible that any of the survival benefits observed in the various $C R T \rightarrow S$ trials could be attained with chemotherapy alone (either $\mathrm{C} \rightarrow \mathrm{S}$ or $\mathrm{C} \rightarrow \mathrm{S} \rightarrow \mathrm{C})$. This is akin to the chemotherapyresponders in MUNICON II. On the other hand, for chemotherapy-nonresponders, it doesn't matter what one does, the survival outcome is unchanged (hence no need for RT at all, in either scenario). Prospective evaluation of these questions are warranted to assess these pertinent questions. Finally, more aggressive chemotherapy with FLOT and DCF 'sandwich' regimens have reported higher pCR rates of $10-12 \%$ and R0 rates of ranging $85-100 \%$ than previous ECF or CF regimens, which merit further testing in several ongoing trials (Table 2) [40-42].

Cross-trial comparisons to determine best treatment approach must be done understanding key differences in eligibility criteria of the trials in question - particularly primary tumor location (Figure 1), stage, and histology as well as surgical technique, pre-treatment staging and nuances of chemoradiotherapy type, dose, and schedule. The Devil is in the details.

Evidence that there is lack of consensus for optimal perioperative treatment of GEC, and in particular EGJ, is reflected by a number of current ongoing trials (Table 2). Fortunately, some of these trials are directly comparing the various perioperative strategies head-to-head. These include 'RESONANCE' and 'SOX', trials which are evaluating the 'sandwich' chemotherapy approach (with various chemotherapy backbones) compared to post-operative chemotherapy alone. The 'ARTIST II', as discussed above, seeks to confirm, prospectively, the perceived post-operative CRT benefit within the 'ARTIST' $\mathrm{LN}+$ subgroup in patients undergoing R0 D2 resection, as well as the intensification of chemotherapy question (SOX vs S-1) in this population in a 4-arm trial [35]. 
Currently, meta-analyses, such as Sjoquist et al., fail to definitively demonstrate superiority of CRT to chemotherapy alone, with the acknowledged numerous caveats of such comparisons (HR $0.88(0.76-1.01 ; \mathrm{p}=0.07))$ [17]. Supporters of CRT point to trends in survival benefit, whereas supporters of chemotherapy alone argue that there are no definitive data to support significant superiority (statistically or clinically) of CRT over chemotherapy alone. To answer the question of whether $\mathrm{C} \rightarrow \mathrm{S} \rightarrow \mathrm{C}$ or $\mathrm{CRT} \rightarrow \mathrm{S}$ is best for EGJ, the planned 366 patient 'MAGIC vs. CROSS Upper GI' trial randomizes patients with AC of the EGJ (I/II/III) to the standard 'MAGIC' or 'CROSS' regimen [60]. Finally, the addition of RT to the perioperative 'sandwich' approach is being evaluated in direct comparison to the standard 'sandwich' approach in the 'CRITICS' (RT post-operative, >D1 surgery, GC and Type III EGJ, $\mathrm{N}=788$ ) [61] and 'TOP GEAR' (RT pre-operative, D2 or $\mathrm{D} 1+$ for EGJ requiring an esophago-gastrectomy, GC and Type II/III EGJ excluding tumors that involve $>2 \mathrm{~cm}$ distal esophagus, $\mathrm{N}=752$ ) [62]. Results of each of these pivotal large randomized phase III trials will be eagerly awaited and will optimistically clarify a number of uncertainties faced currently in this arena. Of course, it is likely that new questions will arise from these studies, and very possible that results may not establish a consensus approach for the perioperative treatment of GEC, if outcomes are similar between comparator groups. Should this be the case (that CRT versus chemotherapy are not substantially different in outcome), other factors such as patient quality of life (ie. requiring daily treatment for $\sim 5$ weeks versus chemotherapy every $2-3$ weeks, toxicity differences, etc.) and/or treatment regimen cost will likely play a role in establishing treatment standards.

\section{Addition of molecularly targeted agents to perioperative therapy}

The integration of 'molecularly targeted' agents to perioperative GEC therapy is complicated, again, by the various available 'backbone' strategies reviewed above. Addition of novel agents to neoadjuvant CRT are underway with anti-EGFR (cetuximab, SCOPE 1 and RTOG0436; panitumumab, ACASOGZ4051), anti-HER2 for HER2+ tumors (trastuzumab, RTOG1010), and anti-angiogenesis (bevacizumab) [63-69]. The RTOG0436 trial, evaluating 350 patients with EGJ and EC (AC and SCC) with paclitaxel, cisplatin, RT with/without cetuximab, revealed only a modest endoscopic CR rate which triggered an early stopping rule in $\mathrm{AC}$ histology; the trial was then open for

Table 3 Medium-throughput targeted sequencing ${ }^{\top}$ of GEC patients undergoing curative intent resection demonstrating profound interpatient molecular heterogeneity

\begin{tabular}{|c|c|c|}
\hline Patient & Oncogene & Tumor suppressor \\
\hline 1 & HER2 Amp+, SRC Amp+, TOP1 Amp+ & \\
\hline 2 & FGFR2 Amp+ & TP53 mt, CDH1 mt \\
\hline 3 & $\begin{array}{l}\text { SRC Amp+, AURKA Amp+, CCND1 Amp+, CDK4 Amp+, } \\
\text { RICTOR Amp+, MDM2 Amp+ }\end{array}$ & CDKN2A/B Loss, ATM mt \\
\hline 4 & HER2 Amp+, PIK3CA mt, CDK6 Amp+ & TP53 mt, PTEN mt \\
\hline 5 & MDM2 Amp+ & \\
\hline 6 & MYCN Amp+ & TP53 mt, FANCA Loss \\
\hline 7 & PIK3CA mt & \\
\hline 8 & & ARID1A mt, ARID2 mt, Smad2 mt, MLL2 mt \\
\hline 9 & HER2 Amp+, PIK3CA mt & TP53 mt \\
\hline 10 & & CDH1 mt, CDH1 Splice Site mt \\
\hline 11 & CCND1 Amp+, EZH2 mt, FGF19 Amp+, FGF3 Amp+, FGF4 Amp+ & \\
\hline 12 & & CDH1 Splice Site mt, CDKN2A mt, ARID1A mt, ARID2 mt \\
\hline 13 & PIK3CA mt, ERBB3 mt, AXL mt, KDR mt & NF1 mt, ARID1A mt, CREBBP mt, CTCF mt, MLH1 mt \\
\hline 14 & & ARID1A mt \\
\hline 15 & KRAS Amp+, CCNE1 Amp+, MDM4 Amp+ & TP53 mt, FBXW7 mt, PTEN mt \\
\hline 16 & HER2 Amp+ & \\
\hline 17 & KRAS mt & TP53 mt, CDKN2A mt \\
\hline 18 & & CDH1 Splice Site mt, LRP1B mt, MLL2 mt \\
\hline 19 & Rictor Amp+ & TP53 mt, KDM6A splice mt \\
\hline 20 & CTNNB1 & TP53 mt \\
\hline 21 & HER2 $\mathrm{mt}$, ERBB3 $\mathrm{mt}$ & TP53 mt (x2), DNMT3A mt, MSH2 mt \\
\hline
\end{tabular}

Legend: Amp+: Amplified, mt: mutation.

${ }^{T}$ Sequencing performed using Foundation One Platform (first generation - 186 genes), except patients 11-21, who were sequenced on the second generation platform (236 genes). 
SCC only [68]. However, a recently reported study observed treatment-related fatalities and inferiority to standard treatment with the addition of cetuximab to CRT in the SCOPE $1(\mathrm{C} \rightarrow \mathrm{CRT}+/$ - cetuximab $\rightarrow \mathrm{S}$; $73 \%$ SCC esophagus, 27\% EGJ AC) trial [63], and served as the basis to fully close all arms of RTOG0436. This observation of potential intolerable toxicity and/or survival detriment with the addition of novel molecularly targeted agents to RT in this setting may hinder further development along these lines [70,71].

On the other hand, introducing novel agents to chemotherapy alone may have less toxicity, and therefore it may be more conducive to evaluate these agents along with perioperative approaches that do not incorporate RT, particularly given the above arguments that there has not been definitive evidence to suggest superiority of CRT based regimens versus non-CRT regimens. A number of studies (MRC OEO5, NCT01761461, NCT01534546, NCT01583361, and FLOT4) [30,35,72-74] are underway (Table 2), evaluating for optimal 'backbone' chemotherapy regimens and sequence. Trials, including ST03, (aka 'MAGIC 2', ECX+/-bevacizumab) [75], seek to address the question of benefit of targeted agents added to chemotherapy backbones. There is also continued evaluation of the PET directed strategies discussed above [49-53,55].

Due to several negative trials in the metastatic setting, the SCOPE-1 results, and the lack of significant clinical CR rate for AC observed in RTOG0436, further evaluation of anti-EGFR therapy is unlikely to be pursued in the perioperative setting, at least in unselected patients. Additionally, there is suggestion that there may be a negative interaction, or at best no improvement, of adjuvant $\mathrm{C} \rightarrow \mathrm{CRT} \rightarrow \mathrm{C}$ in HER2+ patients within the INT0116 trial, albeit with very small numbers [76]. Along with RTOG 1010 evaluating trastuzumab in neoadjuvant CRT approach, it is anticipated that anti-HER2 therapies will be evaluated in HER2+ EGJ/GC patients using the 'sandwich' chemotherapy backbone. However, difficulties in accrual to perioperative clinical trials are exacerbated by the low frequencies of molecular 'oncogenic drivers'; this is the case for HER2+ disease, comprising only $10-20 \%$ of GEC. Potentially 'actionable' oncogenic drivers including MET, KRAS, PIK3CA, FGFR2, SRC and others have even less frequent genomic activation in GEC (Table 3). Therefore, there is great need for novel clinical trial designs and strategies using medium throughput technologies and treatment algorithms with access to multiple therapeutic agents within the same trial, in order to address this increasingly recognized challenge [77].

\section{Conclusions}

GEC is one of the most common malignancies and second highest cause of cancer mortality worldwide. The extensive heterogeneity of etiology, patient ethnicity, tumor location, histology, and trial inclusion/exclusion criteria, have resulted in diverging treatment algorithms with lack of consensus worldwide. Trials are in motion in order to directly address these controversies, yet results will not be available for several years (ie 'MAGIC vs CROSS Upper GI' final data are expected 2021 ). Ultimate treatment plans should be derived by multi-disciplinary review. Regardless, all current standard perioperative approaches improve absolute 5-yr survival for GEC patients 10-15\%, leaving much room for improvement. The promise of 'personalized' cancer care with therapies targeted toward specific molecular aberrations has great potential to significantly improve clinical outcomes. However, there is emerging understanding of the immense molecular heterogeneity within GEC (inter-patient heterogeneity), and even within an individual (intra-patient heterogeneity) (Table 3) [77]. This heterogeneity is a hurdle to advancing GEC treatment via targeted therapies. Current clinical trial design paradigms are challenged by heterogeneity, as they are unable to test targeted therapeutics against low frequency genomic aberrations with adequate power. Collaborative group multicenter and international studies with innovative designs and novel molecular diagnostic technologies will be necessary in order to accomplish these difficult but attainable goals $[77,78]$.

\section{Abbreviations}

GEC: Gastroesophageal cancer, including gastric, esophageal and esophagogastric adenocarcinoma; GC: Gastric cancer; EC: Esophageal adenocarcinoma (distal esophagus); EGJ: Esophagogastric junction;

BE: Barrett's esophagus, metaplasia; AC: Adenocarcinoma; SCC: Squamous

cell cancer (of the proximal/mid esophagus); CRT: Chemoradiotherapy;

RCT: Randomized controlled trial; mOS: Median overall survival;

mPFS: Median progression free survival; mDFS: Median disease free survival.

\section{Competing interests}

The authors declare that they have no competing interests.

\section{Authors' contributions}

The outline was conceived by DC. Both authors contributed to initial drafts, edited versions, and the final version. Both authors read and approved the final manuscript.

\section{Acknowledgements}

For thoughtful discussions and enlightening debates, the authors would like to express gratitude to D. Ilson, A. Venook, M. Shah, B. Polite, V. Villaflor; M. Posner, K. Roggin, E. Choi; I. Waxman, U. Siddiqui; B. Minsky, S. Liauw; J. Hart, and S.Y. Xiao.

Received: 30 July 2013 Accepted: 29 August 2013

Published: 5 September 2013

\section{References}

1. Sehdev A, Catenacci DVT: Gastroesophageal cancer: focus on epidemiology, classification and staging. Discov Med 2013, 16(87):103-111.

2. Konda VJ, Waxman I: Endotherapy for Barrett's esophagus. Am J Gastroenterol 2012, 107:827-833.

3. Mariette C, Piessen G, Briez N, Gronnier C, Triboulet JP: Oesophagogastric junction adenocarcinoma: which therapeutic approach? Lancet Oncol 2011, 12:296-305.

4. Noffsinger A, Waxman I: Preinvasive neoplasia in the stomach: diagnosis and treatment. Clin Gastroenterol Hepatol 2007, 5:1018-1023. 
5. Barreto JC, Posner MC: Transhiatal versus transthoracic esophagectomy for esophageal cancer. World J Gastroenterol 2010, 16:3804-3810.

6. Posner MC, et al: In Cancer of the Upper Gastrointestinal Tract. 1st edition. Edited by Posner M, Vokes EE, Weichselbaum RR. Ontario, Canada: B.C. Decker, Inc; 2002.

7. Feith M, Stein HJ, Siewert JR: Adenocarcinoma of the esophagogastric junction: surgical therapy based on 1602 consecutive resected patients. Surg Oncol Clin N Am 2006, 15:751-764

8. Seevaratnam R, Bocicariu A, Cardoso R, Mahar A, Kiss A, Helyer L, Law C, Coburn N: A meta-analysis of D1 versus D2 lymph node dissection. Gastric Cancer 2012, 15(Suppl 1):S60-S69.

9. Roggin KK, Hemmerich J, Posner MC: Extended follow-up after extended lymphadenectomy for gastric cancer: was it worth the wait? Lancet Oncol 2010, 11:404-405.

10. Macdonald JS: Gastric cancer: Nagoya is not New York. J Clin Oncol 2011, 29:4348-4350.

11. Shah MA, Ajani JA: Gastric cancer-an enigmatic and heterogeneous disease. JAMA 2010, 303:1753-1754

12. Walsh TN, Noonan N, Hollywood D, Kelly A, Keeling N, Hennessy TP: A comparison of multimodal therapy and surgery for esophageal adenocarcinoma. N Engl J Med 1996, 335:462-467.

13. Burmeister BH, Smithers BM, Gebski V, Fitzgerald L, Simes RJ, Devitt $P$, Ackland S, Gotley DC, Joseph D, Millar J, et al: Surgery alone versus chemoradiotherapy followed by surgery for resectable cancer of the oesophagus: a randomised controlled phase III trial. Lancet Oncol 2005, 6:659-668.

14. Tepper J, Krasna MJ, Niedzwiecki D, Hollis D, Reed CE, Goldberg R, Kiel K, Willett C, Sugarbaker D, Mayer R: Phase III trial of trimodality therapy with cisplatin, fluorouracil, radiotherapy, and surgery compared with surgery alone for esophageal cancer: CALGB 9781. J Clin Oncol 2008, 26:1086-1092

15. Urba SG, Orringer MB, Turrisi A, lannettoni M, Forastiere A, Strawderman M: Randomized trial of preoperative chemoradiation versus surgery alone in patients with locoregional esophageal carcinoma. J Clin Oncol 2001, 19:305-313.

16. Gebski V, Burmeister B, Smithers BM, Foo K, Zalcberg J, Simes J: Survival benefits from neoadjuvant chemoradiotherapy or chemotherapy in oesophageal carcinoma: a meta-analysis. Lancet Oncol 2007, 8:226-234.

17. Sjoquist KM, Burmeister BH, Smithers BM, Zalcberg JR, Simes RJ, Barbour A Gebski V, Australasian Gastro-Intestinal Trials G: Survival after neoadjuvant chemotherapy or chemoradiotherapy for resectable oesophageal carcinoma: an updated meta-analysis. Lancet Oncol 2011, 12:681-692.

18. van Hagen $P$, Hulshof MC, van Lanschot JJ, Steyerberg EW, van Berge Henegouwen MI, Wijnhoven BP, Richel DJ, Nieuwenhuijzen GA, Hospers GA, Bonenkamp JJ, et al: Preoperative chemoradiotherapy for esophageal or junctional cancer. N Engl J Med 2012, 366:2074-2084.

19. Macdonald JS, Smalley SR, Benedetti J, Hundahl SA, Estes NC, Stemmermann GN, Haller DG, Ajani JA, Gunderson LL, Jessup JM, Martenson JA: Chemoradiotherapy after surgery compared with surgery alone for adenocarcinoma of the stomach or gastroesophageal junction. N Engl J Med 2001, 345:725-730.

20. Smalley SR, Benedetti JK, Haller DG, Hundahl SA, Estes NC, Ajani JA, Gunderson LL, Goldman B, Martenson JA, Jessup JM, et al: Updated analysis of SWOG-directed intergroup study 0116: a phase III trial of adjuvant radiochemotherapy versus observation after curative gastric cancer resection. J Clin Oncol 2012, 30:2327-2333.

21. Brooks GA, Enzinger PC, Fuchs CS: Adjuvant therapy for gastric cancer: revisiting the past to clarify the future. J Clin Oncol 2012, 30:2297-2299.

22. Macdonald JS, Benedetti J, Smalley S, Haller D, Hundahl S, Jessup J, Ajani J Gunderson L, Goldman B, Martenson J: Chemoradiation of resected gastric cancer: A 10-year follow-up of the phase III trial INT0116 (SWOG 9008) [Abstract]. J Clin Oncol 2009, 27:15s. suppl; abstr 4515.

23. Kim S, Lim DH, Lee J, Kang WK, MacDonald JS, Park CH, Park SH, Lee SH, Kim K, Park JO, et al: An observational study suggesting clinical benefit for adjuvant postoperative chemoradiation in a population of over 500 cases after gastric resection with D2 nodal dissection for adenocarcinoma of the stomach. Int J Radiat Oncol Biol Phys 2005, 63:1279-1285.

24. Kim TH, Park SR, Ryu KW, Kim YW, Bae JM, Lee JH, Choi IJ, Kim YJ, Kim DY: Phase 3 trial of postoperative chemotherapy alone versus chemoradiation therapy in stage III-IV gastric cancer treated with R0 gastrectomy and D2 lymph node dissection. Int J Radiat Oncol Biol Phys 2012, 84:e585-e592.
25. Costa WL Jr, Coimbra FJ, Fogaroli RC, Ribeiro HS, Diniz AL, Begnami MD, Mello CA, Fanelli MF, Silva MJ, Fregnani JH, Montagnini AL: Adjuvant chemoradiotherapy after d2-lymphadenectomy for gastric cancer: the role of $\mathrm{n}$-ratio in patient selection. results of a single cancer center. Radiat Oncol 2012, 7:169.

26. Lee J, Lim Do H, Kim S, Park SH, Park JO, Park YS, Lim HY, Choi MG, Sohn TS, Noh JH, et al: Phase III trial comparing capecitabine plus cisplatin versus capecitabine plus cisplatin with concurrent capecitabine radiotherapy in completely resected gastric cancer with D2 lymph node dissection: the ARTIST trial. J Clin Oncol 2012, 30:268-273.

27. Group MRCOCW: Surgical resection with or without preoperative chemotherapy in oesophageal cancer: a randomised controlled trial. Lancet 2002, 359:1727-1733.

28. Schuhmacher C, Gretschel S, Lordick F, Reichardt P, Hohenberger W, Eisenberger CF, Haag C, Mauer ME, Hasan B, Welch J, et al: Neoadjuvant chemotherapy compared with surgery alone for locally advanced cancer of the stomach and cardia: European organisation for research and treatment of cancer randomized trial 40954. J Clin Oncol 2010, 28:5210-5218

29. Allum WH, Stenning SP, Bancewicz J, Clark Pl, Langley RE: Long-term results of a randomized trial of surgery with or without preoperative chemotherapy in esophageal cancer. J Clin Oncol 2009, 27:5062-5067.

30. Alderson D: A Randomised Controlled Trial Comparing Standard Chemotherapy Followed By Resection Versus Ecx Chemotherapy Followed By Resection In Patients With Resectable Adenocarcinoma Of The Oesophagus. UK Clinical Research Network Study Portfolio; 2005. http://public.ukcrn.org.uk/search/StudyDetail. aspx?StudyID=854.

31. Sakuramoto S, Sasako M, Yamaguchi T, Kinoshita T, Fujii M, Nashimoto A, Furukawa H, Nakajima T, Ohashi Y, Imamura $H$, et al: Adjuvant chemotherapy for gastric cancer with S-1, an oral fluoropyrimidine. N Engl J Med 2007, 357:1810-1820.

32. Sasako M, Sakuramoto $S$, Katai H, Kinoshita T, Furukawa H, Yamaguchi T, Nashimoto A, Fujii M, Nakajima T, Ohashi Y: Five-year outcomes of a randomized phase III trial comparing adjuvant chemotherapy with S-1 versus surgery alone in stage II or III gastric cancer. J Clin Oncol 2011, 29:4387-4393.

33. Paoletti X, Oba K, Burzykowski T, Michiels S, Ohashi Y, Pignon JP, Rougier P, Sakamoto J, Sargent D, Sasako M, et al: Benefit of adjuvant chemotherapy for resectable gastric cancer: a meta-analysis. JAMA 2010, 303:1729-1737.

34. Bang YJ, Kim YW, Yang HK, Chung HC, Park YK, Lee KH, Lee KW, Kim YH, Noh SI, Cho JY, et al: Adjuvant capecitabine and oxaliplatin for gastric cancer after D2 gastrectomy (CLASSIC): a phase 3 open-label, randomised controlled trial. Lancet 2012, 379:315-321.

35. Kang WK: Phase III Randomized Trial of Adjuvant Chemotherapy With S-1 vs S-1/Oxaliplatin \pm Radiotherapy for Completely Resected Gastric Adenocarcinoma: The ARTIST II Trial (ARTIST-II). US National Library of Medicine; 2013. ClinicalTrials.gov [online]. http://clinicaltrials.gov/ct2/show/study/ NCT01761461?term=artist+\|\&rank=1.

36. Kelsen DP, Ginsberg R, Pajak TF, Sheahan DG, Gunderson L, Mortimer J, Estes N, Haller DG, Ajani J, Kocha W, et al: Chemotherapy followed by surgery compared with surgery alone for localized esophageal cancer. N Engl J Med 1998, 339:1979-1984.

37. Kelsen DP, Winter KA, Gunderson LL, Mortimer J, Estes NC, Haller DG, Ajani JA, Kocha W, Minsky BD, Roth JA, Willett CG: Long-term results of RTOG trial 8911 (USA Intergroup 113): a random assignment trial comparison of chemotherapy followed by surgery compared with surgery alone for esophageal cancer. J Clin Oncol 2007, 25:3719-3725.

38. Cunningham D, Allum WH, Stenning SP, Thompson JN, Van de Velde CJ, Nicolson M, Scarffe JH, Lofts FJ, Falk SJ, Iveson TJ, et al: Perioperative chemotherapy versus surgery alone for resectable gastroesophageal cancer. N Engl J Med 2006, 355:11-20.

39. Ychou M, Boige V, Pignon JP, Conroy T, Bouche O, Lebreton G, Ducourtieux M, Bedenne L, Fabre JM, Saint-Aubert B, et al: Perioperative chemotherapy compared with surgery alone for resectable gastroesophageal adenocarcinoma: an FNCLCC and FFCD multicenter phase III trial. J Clin Oncol 2011, 29:1715-1721.

40. Biffi R, Fazio N, Luca F, Chiappa A, Andreoni B, Zampino MG, Roth A, Schuller JC, Fiori G, Orsi F, et al: Surgical outcome after docetaxel-based neoadjuvant chemotherapy in locally-advanced gastric cancer. World J Gastroenterol 2010, 16:868-874. 
41. Ferri LE, Ades S, Alcindor T, Chasen M, Marcus V, Hickeson M, Artho G, Thirlwell MP: Perioperative docetaxel, cisplatin, and 5-fluorouracil (DCF) for locally advanced esophageal and gastric adenocarcinoma: a multicenter phase II trial. Ann Oncol 2012, 23:1512-1517.

42. Homann N, Pauligk C, Luley K, Werner Kraus T, Bruch HP, Atmaca A, Noack F, Altmannsberger HM, Jager E, Al-Batran SE: Pathological complete remission in patients with oesophagogastric cancer receiving preoperative 5-fluorouracil, oxaliplatin and docetaxel. Int J Cancer 2012, 130:1706-1713.

43. Bajetta E, Floriani I, Bartolomeo MD, Intergroup Trial of Adjuvant Chemotherapy in Adenocarcinoma of the Stomach (ITACA-S) trial: Comparison of a sequential treatment with irinotecan (CPT-11) plus 5-fluorouracil (5-FU)/folinic acid (LV) followed by docetaxel and cisplatin versus a 5 -FU/LV regimen as postoperative treatment for radically resected gastric cancer [Abstract]. J Clin Oncol 2012, 30. suppl; abstr LBA4001.

44. Kobayashi M, Tsuburaya A, Yoshida K, Yoshino S, Miyashita Y: Adjuvant paclitaxel followed by oral fluoropyrimidines for gastric cancer: Safety data of the factorial phase III SAMIT trial [Abstract]. J Clin Oncol 2012, 30. suppl 4; abstr 72

45. Yoshida K, Tsuburaya A, Kobayashi M, Yoshino S, Takahashi M, Takiguchi M, Tanabe K, Takahashi N: SAMIT: A phase III randomized clinical trial of adjuvant paclitaxel followed by oral fluorinated pyrimidines for locally advanced gastric cancer [Abstract]. J Clin Oncol 2013, 31. suppl; abstr LBA4002.

46. Fuchs CS, Tepper JE, Niedzwiecki D, Hollis D, Mamon HJ, Swanson R, Haller DG, Dragovich T, Alberts SR, Bjarnason GA, Willett CG, Enzinger PC, Goldberg RM, Venook AP, Mayer RJ: Postoperative adjuvant chemoradiation for gastric or gastroesophageal junction (GEJ) adenocarcinoma using epirubicin, cisplatin, and infusional (Cl) 5-FU (ECF) before and after $\mathrm{Cl}$ 5-FU and radiotherapy (CRT) compared with bolus 5-FU/LV before and after CRT: Intergroup tria CALGB 80101 [Abstract]. J Clin Oncol 2011, 29. suppl; abstr 4003.

47. Sarkaria IS, Rizk NP, Bains MS, Tang LH, Ilson DH, Minsky BI, Rusch WW: Posttreatment endoscopic biopsy is a poor-predictor of pathologic response in patients undergoing chemoradiation therapy for esophageal cancer. Ann Surg 2009, 249:764-767.

48. Weber WA, Ott K, Becker K, Dittler HJ, Helmberger H, Avril NE, Meisetschlager G Busch R, Siewert JR, Schwaiger M, Fink U: Prediction of response to preoperative chemotherapy in adenocarcinomas of the esophagogastric junction by metabolic imaging. J Clin Oncol 2001, 19:3058-3065.

49. Ott K, Weber WA, Lordick F, Becker K, Busch R, Herrmann K, Wieder H, Fink U, Schwaiger M, Siewert JR: Metabolic imaging predicts response, survival, and recurrence in adenocarcinomas of the esophagogastric junction. $J$ Clin Oncol 2006, 24:4692-4698

50. Lordick F, Ott K, Krause BJ, Weber WA, Becker K, Stein HJ, Lorenzen S, Schuster T, Wieder H, Herrmann $K$, et al: PET to assess early metabolic response and to guide treatment of adenocarcinoma of the oesophagogastric junction: the MUNICON phase II trial. Lancet Oncol 2007, 8:797-805.

51. Ott K, Herrmann K, Krause BJ, Lordick F: The value of PET imaging in patients with localized gastroesophageal cancer. Gastrointest Cancer Res 2008, 2:287-294.

52. zum Buschenfelde CM, Herrmann $K$, Schuster T, Geinitz $H$, Langer R, Becker K, Ott K, Ebert M, Zimmermann F, Friess H, et al: (18)F-FDG PETguided salvage neoadjuvant radiochemotherapy of adenocarcinoma of the esophagogastric junction: the MUNICON II trial. J Nucl Med 2011, 52:1189-1196.

53. Lorenzen S: Sequential FDG-PET (Positron Emission Tomography) and Induction Chemotherapy in Locally Advanced Adenocarcinoma of the Esophagogastric Junction (AEG) (HICON). US National Library of Medicine; 2010. ClinicalTrials.gov [online]. http://clinicaltrials.gov/ct2/ show/NCT01271322

54. Goodman KA: Randomized Phase II Trial of PET Scan-Directed Combined Modality Therapy in Esophageal Cancer. US National Library of Medicine; 2011. ClinicalTrials.gov [online]. http://clinicaltrials.gov/ct2/show/ NCT01333033?term $=$ calgb+80803\&rank=1.

55. Lorenzen S, von Gall C, Stange A, Haag GM, Weitz J, Haberkorn U, Lordick F, Weichert W, Abel U, Debus J, et al: Sequential FDG-PET and induction chemotherapy in locally advanced adenocarcinoma of the Oesophagogastric junction (AEG): the Heidelberg imaging program in cancer of the oesophago-gastric junction during Neoadjuvant treatment: HICON trial. BMC Cancer 2011, 11:266

56. Ku GY KD, Strong VE, Schöder H, Janjigian YY, Shah MA, Coit DG, Brennan MF, Capanu M, Ilson DH: Preoperative chemotherapy plus bevacizumab with early salvage therapy based on FDG-PET response in locally advanced gastroesophageal junction and gastric adenocarcinoma. J Clin Onco/ 2013 31(suppl):abstr 4101.

57. Stahl M, Walz MK, Stuschke M, Lehmann N, Meyer HJ, Riera-Knorrenschild J, Langer $\mathrm{P}$, Engenhart-Cabillic R, Bitzer M, Konigsrainer A, et al: Phase III comparison of preoperative chemotherapy compared with chemoradiotherapy in patients with locally advanced adenocarcinoma of the esophagogastric junction. J Clin Oncol 2009, 27:851-856.

58. Alberts SR, Soori GS, Shi Q, Wigle DA, Sticca RP, Miller RC, Leenstra JL, Peller PJ, Wu TT, Yoon HH, Drevyanko TF, Ko S, Mattar Bl, Nikcevich DA, Behrens RJ, Khalil MF, Kim GP: Randomized phase II trial of extended versus standard neoadjuvant therapy for esophageal cancer, NCCTG (Alliance) trial N0849 [Abstract]. J Clin Oncol 2013, 31. suppl; abstr 4026.

59. Seto Y, Chin K, Gomi K, Kozuka T, Fukuda T, Yamada K, Matsubara T, Tokunaga M, Kato $Y$, Yafune A, Yamaguchi T: Treatment of thoracic esophageal carcinoma invading adjacent structures. Cancer Sci 2007, 98:937-942.

60. Reynolds JV: Randomised Clinical Trial of Neoadjuvant and Adjuvant Chemotherapy (MAGIC Regimen) vs. Neoadjuvant Chemoradiation (CROSS Protocol) in Adenocarcinoma of the Oesophagus and Oesophago-gastric Junction. US National Library of Medicine; 2012. ClinicalTrials.gov [online]. http://clinicaltrials.gov/show/NCT01726452

61. Verheji M: A Multicenter Randomized Phase III Trial of Neo-adjuvant Chemotherapy Followed by Surgery and Chemotherapy or by Surgery and Chemoradiotherapy in Resectable Gastric Cancer (CRITICS Study). March 31, 2013. http://clinicaltrials.gov/ ct2/show/NCT00407186?term=NCT00407186\&rank=1.

62. Leong T: A Randomised Phase II/III Trial of Preoperative Chemoradiotherapy Versus Preoperative Chemotherapy For Resectable Gastric Cancer. Australian Cancer Trials; 2009. http://www.australiancancertrials.gov.au/search-clinicaltrials/search.

63. Crosby THC, Falk S, Gollins S, Mukherjee S, Staffurth J, Ray R, Bridgewater JA, Geh I, Cunningham D, Maughan T, Griffiths G: SCOPE 1: a phase II/III trial of chemoradiotherapy in esophageal cancer plus or minus cetuximab. J Clin Oncol 2012, 30(suppl 34):abstr LBA3.

64. Hurt CN, Nixon LS, Griffiths GO, Al-Mokhtar R, Gollins S, Staffurth JN, Phillips CJ, Blazeby JM, Crosby TD: SCOPE1: a randomised phase II/III multicentre clinical trial of definitive chemoradiation, with or without cetuximab, in carcinoma of the oesophagus. BMC Cancer 2011, 11:466.

65. Power DG, Ilson DH: Integration of targeted agents in the neo-adjuvant treatment of gastro-esophageal cancers. Ther Adv Med Oncol 2009, 1:145-165.

66. Meza-Junco J, Au HJ, Sawyer MB: Trastuzumab for gastric cancer. Expert Opin Biol Ther 2009, 9:1543-1551.

67. Safran H: A Phase III Trial Evaluating the Addition of Trastuzumab to Trimodality Treatment of HER2-Overexpressing Esophageal Adenocarcinoma. US National Library of Medicine; 2010. ClinicalTrials.gov [online]. http:// clinicaltrials.gov/ct2/show/NCT01196390?term=RTOG1010\&rank=1.

68. Reed CE: A Phase II Study of Neoadjuvant Therapy With Cisplatin, Docetaxel, Panitumumab Plus Radiation Therapy Followed by Surgery in Patients With Locally Advanced Adenocarcinoma of the Distal Esophagus. US National Library of Medicine; 2008. ClinicalTrials.gov [online]. http://clinicaltrials.gov/ ct2/show/NCT00757172?term=acosog+z4051\&rank=1.

69. Ilson D: A Phase III Trial Evaluating the Addition of Cetuximab to Paclitaxel, Cisplatin, and Radiation for Patients With Esophageal Cancer Who Are Treated Without Surgery. US National Library of Medicine; 2008. ClinicalTrials.gov [online]. http://clinicaltrials.gov/ct2/show/NCT00655876?term=NCT00655876\&rank=1.

70. Crosby T, Hurt C, Falk S, Gollins S, Mukherjee S, Staffurth J, Ray R, Bridgewater JA, Geh I, Cunningham D, Maughan T, Griffiths G: Erbitux Add-On Falls Short in Esophageal Ca [Abstract]. J Clin Oncol 2012, 30. suppl 34; abstr LBA3.

71. Saba N: Trial of XELOX Followed by Radiation Combined With Carboplatin and RAD001 for Esophageal Cancer. US National Library of Medicine; 2011. ClinicalTrials.gov [online]. http://clinicaltrials.gov/ct2/show/NCT01490749? term $=$ NCT01490749\&rank=1.

72. Chen L: Phase III, Randomized, Multicenter, Controlled Evaluation of S-1 and Oxaliplatin as Neoadjuvant Chemotherapy for Advanced Gastric Cancer Patients. US National Library of Medicine; 2012. ClinicalTrials.gov [online]. http://clinicaltrials.gov/ct2/show/NCT01583361?term=NCT01583361\&rank=1.

73. Shen L: A Randomized, Multicenter, Controlled Phase III Study to Compare Perioperative Chemotherapy of Oxaliplatin Combined With S-1(SOX) Versus SOX or Oxaliplatin With Capecitabine (XELOX) as Post-operative Chemotherapy 
in Locally Advanced Gastric Adenocarcinoma With D2 Dissection. US National Library of Medicine; 2012. ClinicalTrials.gov [online]. http://clinicaltrials.gov/ ct2/show/NCT01534546?term=NCT01534546\&rank=1

74. Nordwest K: A Randomized Multicenter Phase IIIIII Study Comparing 5-FU, Leucovorin, Oxaliplatin and Docetaxel (FLOT) Versus Epirubicin, Cisplatin and 5-FU (ECF) in Patients With Locally Advanced Resectable Adenocarcinoma of the Esophagogastreal Junction or the Stomach. US National Library of Medicine; 2010. ClinicalTrials.gov [online]. http://clinicaltrials.gov/ct2/show/ NCT01216644?term=NCT01216644\&rank=1.

75. Cunningham D: A Randomized Controlled Phase II/III Trial of PeriOperative Chemotherapy With or Without Bevacizumab in Operable Oesophagogastric Adenocarcinoma. US National Library of Medicine; 2007. ClinicalTrials.gov [online]. http://clinicaltrials.gov/ct2/show/ NCT00450203?term $=$ NCT00450203\&rank=1.

76. Gordon MA, Gundacker HM, Benedetti J, Macdonald JS, Baranda JC, Levin WJ, Blanke CD, Elatre W, Weng P, Zhou JY, et al: Assessment of HER2 gene amplification in adenocarcinomas of the stomach or gastroesophageal junction in the INT-0116/SWOG9008 clinical trial. Ann Oncol 2013, 24:1754-1761.

77. Catenacci DVT, Polite B, Henderson L, Xu P, Carey GB, Liao WL, Hembrough T, Burrows J, Karrison T, Hart J, Xiao SY, Fitzpatrick C, Marsh R, Vokes E, Olopade O, Villaflor V, Salgia R, Kindler H, Schilsky R: Towards personalized treatment for gastroesophageal adenocarinoma: Strategies to address inter- and intrapatient tumor heterogeneity: PANGEA. [http://www.winsymposium.org/ previous-symposia/win-2013/program-at-a-glance/presentations-july-12/].

78. Stricker T, Catenacci DV, Seiwert TY: Molecular profiling of cancer-the future of personalized cancer medicine: a primer on cancer biology and the tools necessary to bring molecular testing to the clinic. Semin Oncol 2011, 38:173-185.

doi:10.1186/1756-8722-6-66

Cite this article as: Sehdev and Catenacci: Perioperative therapy for locally advanced gastroesophageal cancer: current controversies and consensus of care. Journal of Hematology \& Oncology 2013 6:66.

\section{Submit your next manuscript to BioMed Central and take full advantage of:}

- Convenient online submission

- Thorough peer review

- No space constraints or color figure charges

- Immediate publication on acceptance

- Inclusion in PubMed, CAS, Scopus and Google Scholar

- Research which is freely available for redistribution 